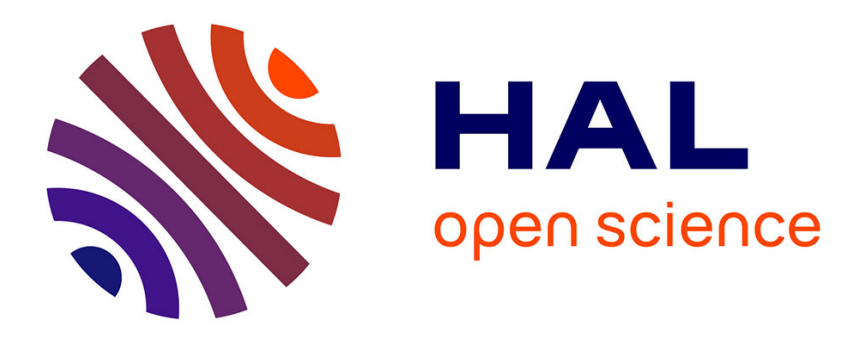

\title{
Robustness of the chiral-icosahedral golden shell I-Au 60 in multi-shell structures
}

\author{
S. Mullins, R. Whetten, H.-Ch. Weissker, X. López-Lozano
}

\section{To cite this version:}

S. Mullins, R. Whetten, H.-Ch. Weissker, X. López-Lozano. Robustness of the chiral-icosahedral golden shell I-Au 60 in multi-shell structures. Journal of Chemical Physics, 2021, 155 (20), pp.204307. 10.1063/5.0060172 . hal-03462070

\section{HAL Id: hal-03462070 \\ https://hal.science/hal-03462070}

Submitted on 1 Dec 2021

HAL is a multi-disciplinary open access archive for the deposit and dissemination of scientific research documents, whether they are published or not. The documents may come from teaching and research institutions in France or abroad, or from public or private research centers.
L'archive ouverte pluridisciplinaire HAL, est destinée au dépôt et à la diffusion de documents scientifiques de niveau recherche, publiés ou non, émanant des établissements d'enseignement et de recherche français ou étrangers, des laboratoires publics ou privés. 


\title{
Robustness of the Chiral-Icosahedral Golden Shell I-Au 60 in Multi-shell structures
}

\author{
S.-M. Mullins, ${ }^{1}$ Robert L. Whetten, ${ }^{2}$ H.-Ch. Weissker, ${ }^{3}$ and X. López-Lozano*1 \\ ${ }^{1)}$ Department of Physics and Astronomy, The University of Texas at San Antonio, One UTSA Circle, San Antonio, TX 78249-0697, \\ USA. \\ 2) Department of Applied Physics and Materials Science, Northern Arizona University, Flagstaff, Arizona 86011, \\ United States \\ ${ }^{3)}$ Aix-Marseille University, CNRS, CINAM, Marseille, France and European Theoretical Spectroscopy Facility (www.etsf.eu). \\ (*Electronic mail: Author to whom correspondence should be addressed: Xochitl.LopezLozano@utsa.edu) \\ (Dated: 16 August 2021)
}

\begin{abstract}
Motivated by the recent theoretical discovery [Nat. Comm. 9, 3352 (2018)] of a surprisingly contracted sixty-atom hollow shell of chiral-icosahedral symmetry $\left(I-\mathrm{Au}_{60}\right)$ of remarkable rigidity and electronegativity, we have explored, via first-principles DFT calculations, its physico-chemical interactions with internal and external shells, enabling conclusions regarding its robustness as well as identifying composite forms in which an identifiable $I-\mathrm{Au}_{60}$ may be realized as a product of natural or laboratory processes. The $I-\mathrm{Au}_{60}$ dimensions and rigidity suggest a templating approach; e.g., an $I_{h}-\mathrm{C}_{60}$ fullerene fits nicely within its interior, as a nested cage. In this work, we have focused on its susceptibility, i.e. the extent to which the unique structural and electronic properties of $I-\mathrm{Au}_{60}$ are modified by incorporation into selected multi-shell structures. Our results confirm that the $I-\mathrm{Au}_{60}$ shell is robustly maintained and protected in various bilayer structures: $I_{h}-\mathrm{C}_{60} @ I-\mathrm{Au}_{60}, I_{h}-\mathrm{Au}_{32} @ I-\mathrm{Au}_{60}^{2+}, \mathrm{Au}_{60}(\mathrm{MgCp})_{12}$, and their silver analogs. A detailed analysis is presented of structural and electronic properties of the selected $I-\mathrm{Au}_{60}$ shell-based nanostructures. We found that the $I-\mathrm{Au}_{60}$ shell structure is quite well retained in several robust forms. In all cases, the $I$-symmetry is preserved, and the I-Au60 shell is slightly deformed only in the case of Ih-C60@I-Au60 system. This analysis serves to stimulate and provide guidance toward the identification and isolation of various $I-\mathrm{Au}_{60}$ shell-based nanostructures, with much potential for future applications. We conclude with a critical comparative discussion of these systems and of the implications for continuing theoretical and experimental investigations.
\end{abstract}

\section{INTRODUCTION}

As has been frequently noted, the low-dimensional nanostructures of gold $(\mathrm{Au})$, including intermetallic combinations with $\{\mathrm{Ag}, \mathrm{Cu}, \mathrm{Pd}, \ldots\}$, have continued to attract great interest in the recent years, originating first in relation to the phenomenal performance of supported gold clusters as lowtemperature catalysts for many important organic chemical transformations. ${ }^{1,2}$ Second, a remarkable variety of twodimensional (2D, e.g. planar close-packed 'rafts') and quasi2D (hollow shells or capsules) has been established in theory and experiment; they are especially competitive with compact (3D) structures as negatively charged clusters (anions).

Trombach et al. ${ }^{1}$ have described "an interesting result for the difference between the cohesive energy of the bulk fcc structure compared to the (111) 2D sheet. Creating the bulk structure from stacking (111) sheets only accounts for $\sim 0.68$ $\mathrm{eV}$ [per atom, or $\sim 18 \%$ ] of the total cohesive energy of the bulk [3.81 eV per atom]..." versus the naive $\sim 50 \%$ expectation from coordination-numbers (6 vs. 12). Coincidentally, we have previously estimated ${ }^{3}$ that the quasi-2D $I-\mathrm{Au}_{72}$ cage (discussed throughout this article for comparison), also lies $0.68 \mathrm{eV} /$ atom higher (less cohesive) than bulk fcc-Au. Assuming the validity of these two estimates, this implies that the 'curved' $I-\mathrm{Au}_{72}$ is isoenergetic with the planar infinite $2 \mathrm{D}$ sheet. (Respectively, these are duals of the fullerene $I-\mathrm{C}_{140}$ structure and the graphene structure.) Although the [neutral] $I-\mathrm{Au}_{60}$ cage (the generating element of the structures proposed in this article) is less stable, at $+0.86 \mathrm{eV}$ per atom, the 'stability gap' with respect to $I-\mathrm{Au}_{72}$ rapidly decreases with increasing negative charge (electron filling), which if extrapolated to the $12 e$ level ( $e / 5$ per atom) may vanish. All this is in striking analogy to the exceptional stability of 'curved' icosahedral carbon fullerenes, especially $I_{h}-\mathrm{C}_{60}\left(12^{-}\right)$, with respect to 2D-graphene.

The ultimate origin of this unusual proclivity for infinite$2 \mathrm{D}$ as well as for finite quasi-2D gold structures is explained by the profound local hybridization $(|5 d z 2> \pm| 6 s>)$ on each Au-atom, wherein $z$ denotes a local axis normal to the plane. Not to mention the generally high electronegativity of gold, manifested also in exceptionally high electron affinities (negative-ion stability). Starting from the planarity of small gold-cluster anions, and increasing the number of atoms, the curved quasi-2D hollow shells (often called 'cages') become more important, consistent with the decrease in curvature energy. High-symmetry shells may further distribute and thereby reduce the strain energy.

Among these shell- or cage-structures, the icosahedral $\left(I_{h}\right)$ shells are the highest symmetry (most uniform). Icosahedral shells investigated previously include the celebrated neutral $I_{h}-\mathrm{Au}_{32}$ cluster, which is competitive with all compact isomeric forms, as well as a series of larger $I_{h}$-symmetry structures $(42,92,122 \text { sites })^{4}$. Karttunen et al. ${ }^{5}$ explored a 72site shell of slightly lower $(I)$ symmetry, $I-\mathrm{Au}_{72}$ (detailed below). The $I_{h}-\mathrm{Au}_{32}$ and $I-\mathrm{Au}_{72}$ structures, in their neutral (uncharged) forms ${ }^{6}$, are notable for supporting closed electronic as well as geometric shells (sometimes called 'doubly magic') for the charge -neutral clusters. ${ }^{7}$ The valence $6 s^{1}$ electrons (one per Au-atom) that form the incipient conduction band are organized into easily recognized angular momentum 
(L) electronic shells, that in the ground electronic state are filled with $2(2 \mathrm{~L}+1)$ electrons, $\mathrm{L}=0,1,2,3, \ldots$, with the familiar result that $2\left(\mathrm{~L}_{\max }+1\right)^{2}$ gives the total number of electrons to completely occupy shells up to $\mathrm{L}=\mathrm{L}_{\max }{ }^{8}{ }^{8}{ }^{9} \mathrm{It}$ is important to recognize that, in these various theoretical-computational works, each icosahedral shell was obtained by geometrical construction of ideal forms, which then undergo only minor adjustments (relaxation) as their quantum electronic structure is calculated; none was obtained from relaxation of a distinct structure/type, in a spontaneous symmetry-changing process. However, in the case of the $I-\mathrm{Au}_{60}$ that we focused on in the present work, which has a close relation to the $I-\mathrm{Au}_{72}$, the starting point in experimental crystallography is quite different, as we explain next.

Now it happens that there are experimental compounds, known collectively as 'ubiquitous icosahedral $\mathrm{A}_{144} \mathrm{X}_{60}$ clusters', where $\mathrm{X}=$ various anionic ligands, and $\mathrm{A}=$ usually $\mathrm{Au}$ but also variously substituted metals ( $\mathrm{Ag}, \mathrm{Cu}, \mathrm{Pd} . .$.$) , that$ share a remarkable history of intense investigation, spanning the past quarter-century, due to factors that ultimately relate to its high symmetry and intrinsic chirality ${ }^{10-13}$. In fact, it has been only during the last few years that the completed chiral icosahedral structure has been unambiguously established in two separate instances and the long-hypothesized I-symmetric structure model was confirmed in marvelously exquisite detail; these were accomplished by total structure determination via single crystal X-ray crystallography, as we now describe ${ }^{14-16}$. First reports of a singular, 'ubiquitous', Au cluster of approximately $\sim 145$-atoms (core mass $\sim 29$ $\mathrm{kDa}$ ) date to $1995-6 .{ }^{17}$ Next, a primitive structure-model was tested, derived directly from the ' $I_{h}-\mathrm{Pd}_{145}$ structure' (hereafter denoted simply by ' $\mathrm{Pd}_{145}$ structure' $)^{18}$ that had been totally solved by 1999. (See brief description immediately below.) Specifically, the $\mathrm{Pd}_{145}$ coordinate-set, when scaled from $\mathrm{Pd}-\mathrm{Pd}$ to $\mathrm{Au}-\mathrm{Au}$ interatomic distances, yielded superior agreement with the $\mathrm{X}$-ray scattering functions determined in the year prior (1998). The $\mathrm{Pd}_{145}$ structure features shells of atoms and ultimately ligand coordination complexes that may be expressed notationally as:

$$
1 @ 12 @\{30+12\} @ 60^{*} @\{30,60 X\}
$$

In 2008, Chaki et al. ${ }^{19}$ demonstrated mass spectrometrically that the clusters comprised only $144 \mathrm{Au}$ atoms (plus the 59-60 thiolate ligands), rather than the expected 145 count established previously for $\mathrm{Pd}_{145}$ by Tran et al. ${ }^{18}$ This surprise prompted O. López-Acevedo et al. ${ }^{20}$ to verify by DFT-based optimization that the more stable version centered on a vacancy, i.e. its central $I_{h}-\mathrm{Au}_{12}$ cage is hollow, lacking a central atom, consistent with the reformulation $\mathrm{Au}_{144}(\mathrm{SR})_{60}$. Subsequently, several groups pursued the theoretical investigation of this newly predicted structure model using symmetrized coordinate sets. ${ }^{11,12}$ In this way, it could be established theoretically that the 'staple-motif' binding of 60 thiolates (30 pairs) in this case necessitates the reduction from full icosahedral $\left(I_{h}\right)$ symmetry to the chiral-icosahedral $(I)$, which also generates additional space for the ligands. An analysis of the symmetry (group-theoretical designation) of the $\mathrm{Au}_{144}\left(\mathrm{SCH}_{3}\right)_{60}{ }^{12}$ and the simplified $\mathrm{Au}_{144}(\mathrm{Cl})_{60}{ }^{11}$ confirmed

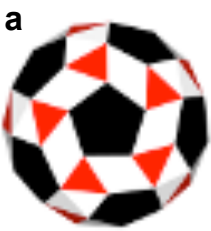

Ideal - 3.3.3.3.5*

d

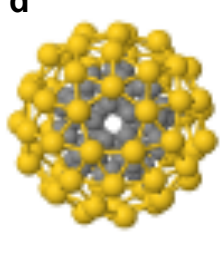

$I_{h}-\mathrm{C}_{60} @ I-\mathrm{Au}_{60}$ b

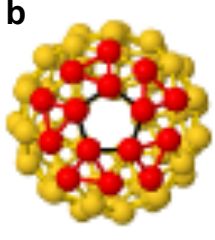

$I-\mathrm{Au}_{60}$

e

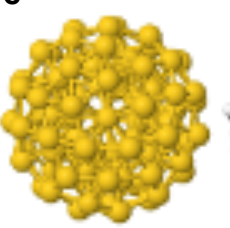

$I_{h}-\mathrm{Au}_{32} @ I-\mathrm{Au}_{60}{ }^{2+}$
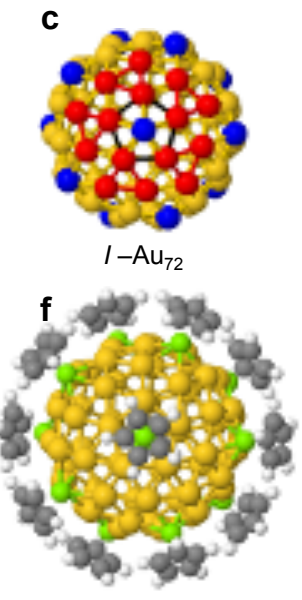

$I-\mathrm{Au}_{60}(\mathrm{MgCp})_{12}$
FIG. 1. (a) Snub dodecahedron Archimedean polyhedron (b) the ball-and-stick atomic model of the $I-\mathrm{Au}_{60}$ shell. Some $\mathrm{Au}$ atoms located in the pentagonal facet are displayed in different colors to highlight the pentagons and triangles of the snub dodecahedron. (c) $I-\mathrm{Au}_{72}$ : Composed by a 12 -atom icosahedron and a 60 -atom snub dodecahedron, proposed from geometric principles. (d) $I_{h}-\mathrm{C}_{60} @ I-$ $\mathrm{Au}_{60}$ : The $I_{h}-\mathrm{C}_{60}$ fullerene core is placed inside the $I-\mathrm{Au}_{60}$. (e) $I_{h}-\mathrm{Au}_{32} @ I-\mathrm{Au}_{60}^{2+}$ : The core is composed by an $I_{h}-\mathrm{Au}_{32}$ core $^{6}$ and the $I-\mathrm{Au}_{60}$ shell surrounding it. (f) $\mathrm{Au}_{60}(\mathrm{MgCp})_{12}$ : The structure is composed by the $I-\mathrm{Au}_{60}$ shell with 12 stellating Magnesium atoms located at the 12 pentagons. Above each of the $\mathrm{Mg}$ ions is placed a cyclopentadienide $(\mathrm{Cp})$ anion with five carbon and hydrogen atoms.

that the chiral icosahedral symmetry (group $I$, also known as 532), holds for charge-states $\{+2,+4,-8\}$ that assure a non-degenerate ground state, i.e. for which the Jahn-Teller Theorem does not predict spontaneous symmetry-lowering deformations.

The size and the high stability of the monolayer protected 144-atom noble-metal cluster compound $\mathrm{Au}_{144}(\mathrm{SR})_{60}{ }^{10-13,18}$ motivated the study of the stability and chirality of its four concentric constitutive shells: the inner core [two shells of $(12)+(30+12) \mathrm{Au}$ atoms that have no coordination to ligands]; the Grand Core (114 Au atoms) consisting of the inner core plus 60 surface $\mathrm{Au}$ atoms $\left(\sim I_{h}-\mathrm{Au}_{60}\right.$ shell), each singly coordinated to thiolates (RS-) and the final (4th) shell, a protective layer conformed by 30 staple-motif units (RS$\mathrm{Au}(\mathrm{I})-\mathrm{SR})^{12,13}$. Specifically, during our investigation we extracted, analyzed and performed a structural optimization of the $\mathrm{Au}_{60}$ shell. This shell structure is referred as $\sim I_{h}-\mathrm{Au}_{60}$ (or quasi $I_{h}-\mathrm{Au}_{60}$ ) for it deviates from the $I_{h}$-symmetry; its Hausdorff Chirality Measure (HCM) is $\sim 0.02$ (or 2\%) as opposed to the ideal $\left[3.3 .3 .3 .5^{*}\right]$ polyhedron structures of $\sim$ 0.10 (up to $10 \%$ ). We expected the collapse of this $\sim I_{h}-$ $\mathrm{Au}_{60}$ structure into a compact cluster, similar or close to the $C_{1}-\mathrm{Au}_{60}$ presented in Ref. ${ }^{21}$ However, we found an extraordinary (robust) and unprecedented structural transition. The $\sim I_{h}-\mathrm{Au}_{60}$ shell, which approximates a rhombicosidodecahe- 
dron [3.4.5.4], an Archimedean solid, transforms into another structure resembling the 60-vertex Archimedean solid geometry, namely, the snub dodecahedron [3.3.3.3.5*], see Fig. 1(a) and (b). First the extracted $\sim I_{h}-\mathrm{Au}_{60}$ shell contracts spontaneously and then transforms coherently into a final structure $I-\mathrm{Au}_{60}$ of remarkable perfection, in which all 60 atoms are in symmetry-equivalent sites and have five (5) unusually short interatomic distances (bonds). This structure/shell has 92 faces, 12 are pentagons $\square$ (black) and the other 80 are triangles: 20 equilateral $\triangle$ (red) and 60 isosceles $\Delta$ (white), see Fig. 1(a). Each atom has two pentagonal edges with lengths of $2.70 \AA$, one triangular edge of $2.74 \AA$ and two triangular edges of $2.79 \AA$ for the equilateral triangles, see Table I. Fig. 1(b) shows the ball-and-stick atomic model of the optimized $I-\mathrm{Au}_{60}$ shell.

The $I-\mathrm{Au}_{60}$ structure thus provides a unique instance of stability wherein all (60) atoms are equivalent, without the presence of any other supporting elements. This exceptional symmetry characteristic has special consequences in its electronic and optical properties that we reported in detail ${ }^{3}$. Its special properties make it ideal for its production: (i) structurally, it is $I$-spherical with a convenient (1.178-nm) diameter and minimum surface area; (ii) mechanically, its strong and short bonds, all tangential to the surface of the sphere, render it unusually rigid or resistant to deformation; (iii) electronically, the prevalent $\left\{6 s-5 d z^{2}\right\}$ hybridization (relativity derived) favors 2D-directional bonding $5,22,23$; (iv) (electro) chemically, its electronic-shell closures at $\left\{0,6^{-}, 12^{-}\right\}$combined with a high electronegativity may greatly reduce its reactivity and increase the stability of its anionic compounds.

The $I-\mathrm{Au}_{60}$ shell-structure has not been yet experimentally characterized so far, and it may appear an unlikely candidate for experimental detection and physical isolation or chemical synthesis, in view of the greater cohesion of filled (compact) structures and the presumed reactivity of its exterior surface. However, based on its dimension (size) and rigidity (i-ii) we suggested a templating approach and indicated different strategies to preserve/isolate it through various cores as well as potential synthesis pathways ${ }^{3}$. Specifically, we found that an $I_{h}-\mathrm{C}_{60}$ (Buckyball) $^{24}$ fits almost perfectly within its interior void, i.e. to generate nested cages like $I_{h}-\mathrm{C}_{60} @ I-\mathrm{Au}_{60}$. Different initial geometries of hypothetical stabilized clusters were proposed and its structural stability was investigated, namely $I_{h}-\mathrm{C}_{60} @ I-\mathrm{Au}_{60}, I_{h}-\mathrm{Au}_{32} @ I-\mathrm{Au}_{60}^{2+}$ bilayer structure and $I-\mathrm{Au}_{60}(\mathrm{MgCp})_{12}$, see Fig. 1(d), (e) and (f). Preliminary first-principles calculations based on Density Functional Theory (DFT) demonstrate that the $I-\mathrm{Au}_{60}$ shell is well maintained and it can be protected further. The icosahedral symmetry is preserved and the shell is slightly deformed only for the case of $I_{h}-\mathrm{C}_{60} @ I-\mathrm{Au}_{60}$ system. Notwithstanding, a complete report of the structural and electronic properties of these $I-\mathrm{Au}_{60}$-based core-shell structures with their constituent shells has not yet appeared until now.

The prediction and investigation of additional highsymmetry $\mathrm{Au}$ shells with a $\mathrm{C}_{60}$ core could open applications in a variety of areas such as functionalized core-shell structures or thin films. In addition, these clusters may be stabilized by a surface ligand shell. In this paper, we present a detailed ab initio DFT study of the structural and electronic properties of the $I-\mathrm{Au}_{60}$-based core-shell structures mentioned above. We are particularly interested in gaining a better understanding of how the structure's morphology of surrounding shells influences the fundamental properties of the $I-\mathrm{Au}_{60}$ nanoshell. Specifically, we are interested in determining the structural stability of the $I-\mathrm{Au}_{60}$ shell.

\section{METHODS}

In our investigation of the systems constructed as described below, we performed first-principles spin-polarized DFT calculations as implemented in the SIESTA code ${ }^{25,26}$. We used norm-conserving Troullier-Martins (TM) pseudopotentials $(\mathrm{PPs})^{27}$ with scalar relativistic correction, which include the $d$ electrons in the valence, i.e., with 11 valence electrons for each atom. The generalized-gradient approximation (GGA) for the exchange-correlation functional of PerdewBurke-Ernzerhof (PBE) was used ${ }^{28}$. The wavefunctions were expanded in a double- $\zeta$ polarized basis set $(\mathrm{D} \zeta \mathrm{P})$. After a thorough series of convergence tests, 550 Rydberg cutoff for the density integration grid and a density matrix convergence criterion of $10^{-4} \mathrm{eV}$ were chosen. All the $\mathrm{Au}$ atoms were allowed to relax using the conjugate gradient minimization method until the forces were smaller than 0.005 $\mathrm{eV} / \AA$. We used periodic boundary conditions and a simple cubic superlattice with a cell size of $40 \AA$. These parameters gave a bulk FCC cohesion energy of $3.20 \mathrm{eV} /$ atom and a lattice constant of $4.18 \AA$ (interatomic distance $2.95 \AA$ ), $+2.4 \%$ larger than the experiment, which is typical of the GGA functional.

Inspired by the size of the $I-\mathrm{Au}_{60}$ shell and interior void, we created core-shell structures using, as cores, either the $I_{h}$ $\mathrm{C}_{60}$ fullerene ${ }^{24}$, or the $I_{h}-\mathrm{Au}_{32}$ stellated dodecahedron ${ }^{6}$; alternatively an encapsulating shell of twelve (12) magnesium $\left(\mathrm{Mg}^{2+}\right)$ ions and twelve cyclopentadienide $\left(\mathrm{Cp}^{-}\right) \mathrm{C}_{5} \mathrm{H}_{5}$ ligands. The initial geometries are: (i) $I_{h}-\mathrm{C}_{60} @ I-\mathrm{Au}_{60}$. The $I_{h}-$ $\mathrm{C}_{60}$ fullerene core was placed inside the $I-\mathrm{Au}_{60}$ and aligned according to the shared icosahedral symmetry, see Fig. 1(d). (ii) $I_{h}-\mathrm{Au}_{32} @ I-\mathrm{Au}_{60}^{2+}$. This is a bilayer structure whose core is composed by an $I_{h}-\mathrm{Au}_{32}$ cluster (Johansson et al., $\operatorname{Ref}^{6}$ ) and the chiral icosahedral $I-\mathrm{Au}_{60}$ shell surrounding it, see Fig. 1(e). (iii) $I-\mathrm{Au}_{60}(\mathrm{MgCp})_{12}$. This structure is composed by the $I-\mathrm{Au}_{60}$ shell with 12 stellating magnesium ions located at the 12 pentagons. Above each of the $\mathrm{Mg}$ ions is placed a $\mathrm{Cp}^{-}$anion with five carbon and hydrogen atoms $\mathrm{C}_{5} \mathrm{H}_{5}{ }^{-}$ (Clayborne et al., Ref. ${ }^{29}$ ), see Fig. 1(f).

In order to compare the properties of the $I-\mathrm{Au}_{60}$-based core-shell structures with their constituent shells of similar size, we considered the following isolated nanoshells: the chiral icosahedral $I-\mathrm{Au}_{60}$, Fig. 1(b); the I-Au $\mathrm{Au}_{72}$, Fig. 1(c); and the $I_{h}-\mathrm{Au}_{32}$ and the $I_{h}-\mathrm{C}_{60}$ [interior portions of Figs. $1(\mathrm{~d})$ and (e)]. , $^{3,6,24}$ Table I collects the radii, bond-lengths, diameter 
and chiral index of these isolated and optimized shells, as obtained with the computational method described above. The charge-neutral $I_{h}-\mathrm{Au}_{32}$ and $I-\mathrm{Au}_{72}$ shell structures are 'doubly magic' for supporting closed electronic as well as geometric shells. ${ }^{7}$ Moreover, the icosahedral $I-\mathrm{Au}_{72}$ obtained as a compound of concentric polyhedra is of special importance, not only for its potential as an enantioselective catalyst ${ }^{5}$ but also this is the smallest known chiral molecule that exhibits spherical aromaticity. ${ }^{22,23}$

In addition, for comparison purposes we considered the equivalent core-shell structures systems (i-ii-iii) in silver (Ag), i.e., by replacing $\mathrm{Au}$ for $\mathrm{Ag}$ : (iv) $I_{h}-\mathrm{C}_{60} @ I-\mathrm{Ag}_{60}$, (v) $I_{h^{-}}$ $\mathrm{Ag}_{32} @ I-\mathrm{Ag}_{60}^{2+}$ and (vi) $I-\mathrm{Ag}_{60}(\mathrm{MgCp})_{12}$. Occasionally for concision, we will refer to these six (6) core-shell structures as $I_{h}-\mathrm{C}_{60} @ I-\mathrm{A} i_{60}, I_{h}-\mathrm{A} i_{32} @ I-\mathrm{A} i_{60}^{2+}$ and $I-\mathrm{A} i_{60}(\mathrm{MgCp})_{12}$, where $i=u$ for gold (Au) and $i=g$ for silver $(\mathrm{Ag})$. The Au - $\mathrm{Au}, \mathrm{Ag}-\mathrm{Ag}, \mathrm{C}-\mathrm{Au}$ and $\mathrm{C}-\mathrm{Ag}$ bond-lengths will also be symbolized jointly as $\mathrm{A} i-\mathrm{A} j$ and $\mathrm{C}-\mathrm{A} i, j$, respectively. All the symmetry-group assignments were calculated with the Jmol tool $^{30}$ 'Calculate Pointgroup' using a tolerance of $0.2-\AA$, unless explicitly stated otherwise.

\section{Selection of the $I-\mathbf{A u}_{60}$-Based Multi-shells Models}

Since their discovery in 1985, fullerenes have drawn interest for applications in nanoelectronic devices. Best-known of the fullerenes is the $\mathrm{C}_{60}$ "Buckyball"24. Among the few investigations of the interactions of gold shells with $\mathrm{C}_{60}$ is the study of the structural stability of gold fullerene-like structures covering the $I_{h}-\mathrm{C}_{60}$ molecule for the icosahedral shell series of $\mathrm{Au}_{32}, \mathrm{Au}_{60}, \mathrm{Au}_{66}$ and $\mathrm{Au}_{92}$, shells by Batista et $a l .{ }^{31}$, wherein a cluster with icosahedral symmetry denoted by $\mathrm{Au}_{92} \mathrm{C}_{60}$ was identified as the most stable. This cluster is composed by 92 gold atoms covering the fullerene and it was found after the structural relaxation of the initial geometry $I_{h}-\mathrm{C}_{60} @ I-\mathrm{Au}_{92}$. It is also reported that most of the Au atoms have coordination 6 and that the average distance between the carbon and gold layers is $3.6 \AA$. In addition, it has shown that the functionalization of this cluster with thiol molecules can further stabilized the structure. Batista did not test the stability of the $I-\mathrm{Au}_{60}$ shell we predicted ${ }^{10}$, however. The $\mathrm{Au}_{60}$ structure they studied had the same morphology as the $\mathrm{C}_{60}$, namely a truncated icosahedron, composed of 12 pentagons and 20 hexagons. The relaxation of their $\mathrm{Au}_{60}$ resulted in a deformation where the hexagons and pentagons collapse into triangles and holes are created in the Au shell. Instead, we find the short and strong $\mathrm{Au}-\mathrm{Au}$ bonding in the $I-\mathrm{Au}_{60}$ permits all $60 \mathrm{Au}$ atoms to fit compactly around the $I_{h}-\mathrm{C}_{60}$, versus only 32 for the alkaline-earth metals $(\mathrm{Ca}, \mathrm{Sr}$, $\mathrm{Ba}$ ) explored by Martin and coworkers ${ }^{32}$. The gas aggregation of $60 \mathrm{Au}$ atoms upon a $\mathrm{C}_{60}$ core is thus predicted. Therefore, we investigated the $I_{h}-\mathrm{C}_{60} @ I-\mathrm{Au}_{60}$ and $I_{h}-\mathrm{C}_{60} @ I-\mathrm{Ag}_{60}$ core-shell structures.

Another structure which has been used as a core for multi-layered nanoclusters is the 32-atom icosahedron. The icosahedral $\mathrm{Au}_{32}$ was first discovered by Johansson et al. in 2004 and the first larger (> 20 atoms) shell to be reported ${ }^{6}$.
The $\mathrm{WAu}_{12}$ was discovered previously where the $\mathrm{Au}_{12}$ icosahedron shell surrounds a tungsten atom. The isolated $\mathrm{Au}_{12}$ icosahedron is unstable, however. Theoretical investigations of the $\mathrm{Au}_{32}$ has shown that it is highly stable, even more stable than the tetrahedral $\mathrm{Au}_{20}$ cluster ${ }^{33}$. It has a diameter of approximately $0.8 \mathrm{~nm}$, roughly the size of the $\mathrm{C}_{60}$, which makes for a nice fit within the $I-\mathrm{Au}_{60}$ shell structure. The $\mathrm{Ag}_{32}$ was already discussed at the time of the discovery of $\mathrm{Au}_{32}$, however. In 2012 Chakraborty et al. ${ }^{34}$ isolated an abundant larger silver thiolate cluster that was identified (or modeled) as $\mathrm{Ag}_{152}(\mathrm{SR})_{60}, \mathrm{R}=\mathrm{CH}_{2} \mathrm{CH}_{2} \mathrm{Ph}$ cluster composed of a stable 92-atom Ag core-shell structure surrounded by 60 $\mathrm{Ag}$ and 60 thiolates. The $\mathrm{Ag}_{92}$ core is composed by the $\mathrm{Ag}_{32}$ icosahedral core surrounded by a chiral icosahedral $I-\mathrm{Ag}_{60}$ shell. In this respect the $I_{h}-\mathrm{Ag}_{32} @ I-\mathrm{Ag}_{60}^{2+}$ has previously been investigated. These models (including charge $2+$ ) have been motivated by the results of Chakraborty et al. ${ }^{34}$, which are hereby confirmed to apply to gold as well as silver $I-\mathrm{Ag}_{92}$ (hollow) shells.

Finally, we propose the $I-\mathrm{Au}_{60}(\mathrm{MgCp})_{12}$ and $I-$ $\mathrm{Ag}_{60}(\mathrm{MgCp})_{12}$ structures as models systems decorated, in accordance with well established chemical precedent ${ }^{35}$ by electropositive ferrocene-like $\mathrm{CpM}^{+}$groups, wherein $\mathrm{Cp}=C_{5 h}-\mathrm{C}_{5} \mathrm{H}_{5}$ - ligand and $\mathrm{M}$ is a divalent metal cation. Here, our goal is to investigate the stability of a hollow $\mathrm{Au}$ shell of this size when decorated with $12 \mathrm{Cp}$ anion ligands by analogy to the experimental known and theoretically confirmed $\mathrm{Al}_{50} \mathrm{Cp}_{12}^{*}$, Ref. 29. The $12 \mathrm{Cp}$ anion ligands are chosen in order to achieve an electronic shell closing of 72 valence electrons which occurs in hollow shells, as in the neutral $\mathrm{Au}_{72}{ }^{5}$.

\section{RESULTS}

\section{A. Alignment of Core and Shells}

For the particular $I_{h}-\mathrm{C}_{60} @ I-\mathrm{A} i_{60}$ core-shell initial configurations, two initial orientations of both of the initial geometries $I_{h}-\mathrm{C}_{60} @ I-\mathrm{Au}_{60}$ and $I_{h}-\mathrm{C}_{60} @ I-\mathrm{Ag}_{60}$ were considered: (a) an alignment of the shared icosahedral symmetries and (b) a random orientation of the shells. While each $\mathrm{C}_{60}, \mathrm{Au}_{60}$, and $\mathrm{Ag}_{60}$ shells maintained its respective starting symmetry after relaxation, the cores rotated with respect to the shells and all relaxations converged to a final structures with an overall $\mathrm{D}_{5}$-symmetry. Upon inspection of the $\mathrm{C}-\mathrm{A} i, j$ interatomic distances, however, we found a more uniform bonding behavior suggesting the $\mathrm{C}-\mathrm{A} i, j$ bonds might play a large part in determining the orientation, and thus symmetry, of the final relaxed structure. 

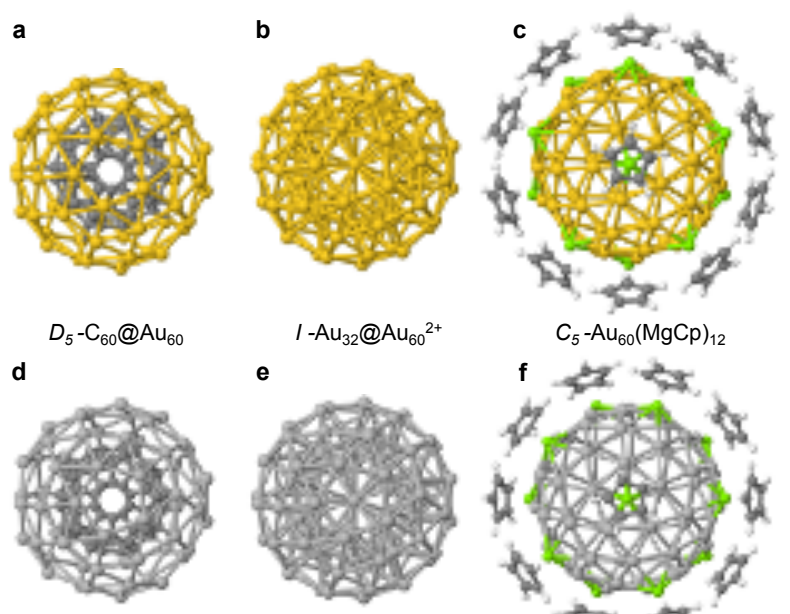

$D_{5}-\mathrm{C}_{60} @ \mathrm{Ag}_{60}$

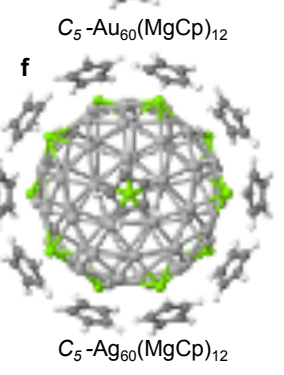

FIG. 2. Optimized structures based on the $I-\mathrm{Au}_{60}$ shell. (a) $I_{h}-$ $\mathrm{C}_{60} @ I-\mathrm{Au}_{60}$, (b) $I_{h}-\mathrm{Au}_{32} @ I-\mathrm{Au}_{60}^{2+}$, (c) $C_{5}-\mathrm{Au}_{60}(\mathrm{MgCp})_{12}$, (d) $I_{h^{-}}$ $\mathrm{C}_{60} @ I-\mathrm{Ag}_{60}$, (e) $I_{h}-\mathrm{Ag}_{32} @ I-\mathrm{Ag}_{60}^{2+}$, and (f) $C_{5}-\mathrm{Ag}_{60}(\mathrm{MgCp})_{12}$.

\section{B. Structural Parameters of The Optimized Forms}

In this section, we report how the structural features in the $I-\mathrm{Au}_{60}$ shell change with the introduction of a core or when it is decorated by ligands. Figure 2 shows the ball-and-stick atomic models of the optimized core-shell structures obtained from the atomic relaxation of the initial geometries proposed, shown in Fig. 1: $I_{h}-\mathrm{C}_{60} @ I-\mathrm{A} i_{60}, I_{h}-\mathrm{A} i_{32} @ I-\mathrm{A} i_{60}^{2+}$ bilayer structure and $I-\mathrm{A} i_{60}(\mathrm{MgCp})_{12}$, respectively. Figure 3 and Fig. 4 show the radial and interatomic distances of the optimized $I_{h}-\mathrm{C}_{60} @ I-\mathrm{A} i_{60}, I_{h}-\mathrm{A} i_{32} @ I-\mathrm{A} i_{60}^{2+}$ and $I-\mathrm{A} i_{60}(\mathrm{MgCp})_{12}$ clusters. The $I-\mathrm{A} i_{60}$ has been included for comparison purposes.

\section{I-A $u_{60}$-Based Multi-shells}

For the case of the isolated $I-\mathrm{Au}_{60}$ shell, as reported previously, the radius is $5.90 \AA$, and we determine the three distinct nearest neighbor $\mathrm{Au}-\mathrm{Au}$ distances, each atom has two pentagonal $\square$ edges of length $2.70 \AA$, one triangular edge in the isosceles triangles $\triangle$ of $2.74 \AA$ and two triangular edges in the equilateral triangles $\triangle$ of $2.79 \AA$, see first row of Table I. Separately, a chiral icosahedral $I-\mathrm{Ag}_{60}$ shell was obtained when the $I-\mathrm{Au}_{60}$ shell was used as template for the initial geometric configuration, then the Au atoms were replaced by Ag and subsequently a DFT structural optimization, in which all the $\mathrm{Ag}$ atoms were allowed to relax, was performed. Compared with the $I-\mathrm{Au}_{60}$, the final optimized $I-\mathrm{Ag}_{60}$ shell structure has a slightly larger radius of $6.13 \AA$, roughly $3.9 \%$ larger than the golden shell. The $I-\mathrm{Ag}_{60}$ is also more regular than the $I-\mathrm{Au}_{60}$ with three distinct nearest neighbor $\mathrm{Ag}-\mathrm{Ag}$ distances at $2.82 \AA(\triangle), 2.86 \AA(\triangle)$, and $2.88 \AA(\triangle)$, see Table I. The isolated $I_{h}-\mathrm{Au}_{32}$ shell has two radii at $3.97 \AA$ and $4.50 \AA$ corresponding to the 20 -atom dodecahedron and 12-atoms stellating the pentagons and has two $\mathrm{Au}-\mathrm{Au}$ bond-lengths at $2.76 \AA$ and $2.83 \AA$. The radius of the isolated $I_{h}-\mathrm{C}_{60}$ fullerene is calculated to be $3.65 \AA$ and there are 2 characteristic $\mathrm{C}-\mathrm{C}$ bond-lengths at $1.43 \AA$ and $1.49 \AA$. On the other hand, the isolated $I_{h}-\mathrm{Ag}_{32}$ shell has two radii at $4.10 \AA$ and $4.66 \AA$ corresponding to the 20 -atom dodecahedron and 12-atoms stellating the pentagons and has two $\mathrm{Ag}-\mathrm{Ag}$ bond-lengths at $2.85 \AA$ and $2.93 \AA$. The radius of the isolated $I_{h}-\mathrm{C}_{60}$ fullerene is calculated to be $3.65 \AA$ and there are 2 characteristic $\mathrm{C}-\mathrm{C}$ bond-lengths at $1.43 \AA$ and $1.49 \AA$.

(i) $I_{h}-\mathrm{C}_{60} @ I-\mathrm{Au}_{60}$. Fig. 2(a) shows the fully optimized $\mathrm{C}_{60} @ \mathrm{Au}_{60}$ core-shell structure. The radius of the $\mathrm{C}_{60}$ core decreases slightly $(<2 \%)$, from 3.65 to $3.60 \AA$ and the radius of the $\mathrm{Au}_{60}$ shell increases 4 to $6 \%$ with $\mathrm{Au}$ atoms spread between $6.12 \AA$ and $6.25 \AA$, see top panel left of Figure 3 . Both constitutive shells retain its $I_{h}$ and $I$ symmetries, respectively, whereas the symmetry of the entire system is $D_{5}$. The contracted (expanded) radial distance in the $\mathrm{C}_{60}\left(\mathrm{Au}_{60}\right)$ shells are also reflected in the interatomic distributions. Both the $\mathrm{C}-\mathrm{C}$ and $\mathrm{Au}-\mathrm{Au}$ bonds become less uniform in the optimized core-shell structure $D_{5}-\mathrm{C}_{60} @ \mathrm{Au}_{60}$ and are instead distributed in a range between $2.81-2.92 \AA$ for the $\mathrm{Au}-\mathrm{Au}$ and $1.43-1.48 \AA$ for the $\mathrm{C}-\mathrm{C}$ interatomic distances. The $\mathrm{C}$ - Au bonds range from 2.51 to $2.97 \AA$ and are associated with the overall $\mathrm{D}_{5}$-symmetry. Figure 5 (a) shows the optimized $D_{5}-\mathrm{C}_{60} @ \mathrm{Au}_{60}$ cluster along the five-fold symmetry axis with the $\mathrm{C}-\mathrm{Au}$ distances grouped and colored by length. There are two sets of pentagons in the relaxed $D_{5}-\mathrm{C}_{60} @ \mathrm{Au}_{60}$ and $D_{5}-\mathrm{C}_{60} @ \mathrm{Ag}_{60}$, which are aligned along the single five-fold symmetry axis. Perpendicular to the five-fold axis are 5 two-fold axes of rotation which pass between the atoms colored red in Fig. 5(a).

(ii) $I_{h}-\mathrm{Au}_{32} @ I-\mathrm{Au}_{60}^{2+}$. Upon relaxation of the initial configurations of the (2) [concentric] shells, the optimized $I$-symmetric structure of this system is obtained. The optimized $I-\mathrm{Au}_{32} @ \mathrm{Au}_{60}^{2+}$ core-shell structure has three radii at $3.80 \AA, 4.78 \AA$ and $6.39 \AA$, associated with a decrease in the radial distance of the dodecahedron of $\mathrm{Au}_{32}$, an increase of the radius of the 12 atoms stellating the pentagons of $\mathrm{Au}_{32}$ (now between the shells), and an increase of $\sim+8 \%$ of the outermost $\mathrm{Au}_{60}$ shell. The symmetry of each shell in the optimized system is shown in Table I. The three distinct nearest neighbor $\mathrm{Au}-\mathrm{Au}$ distances in the icosahedral $\mathrm{I}-\mathrm{Au}_{60}$ shell of $2.70 \AA(\triangle), 2.74 \AA(\triangle)$, and $2.79 \AA(\triangle)$, become $3.03 \AA, 2.83 \AA$, and $2.92 \AA$, respectively. However, both shells the $\mathrm{Au}_{32}$ and the $\mathrm{Au}_{60}$ retain the $I_{h}$ and $I$ (icosahedral) symmetry, respectively. Moreover, there are two other $\mathrm{Au}-\mathrm{Au}$ bond-lengths of $2.71 \AA$ and $2.9 \AA$ between the shells.

(iii) $I-\mathrm{Au}_{60}(\mathrm{MgCp})_{12}$. The optimized structure of $I-$ $\mathrm{Au}_{60}(\mathrm{MgCp})_{12}$ shows the least change with respect to the isolated $I-\mathrm{Au}_{60}$. The $\mathrm{Au}_{60}$ shell has icosahedral symmetry and the overall symmetry of the composite system is $C_{5}$ due to the alignment of the substructures. The radius of the $\mathrm{Au}_{60}$ shell increases only slightly from $5.90 \AA$ to $5.94 \AA$. The 
TABLE I. Radii, Bondlengths, diameter in Angstroms $\AA$ and chiral index $(\%)$ of $I_{h}-\mathrm{C}_{60} @ I-\mathrm{A} i_{60}, I_{h}-\mathrm{A} i_{32} @ I-\mathrm{A} i_{60}^{2+}$ and $I-\mathrm{A} i_{60}(\mathrm{MgCp})_{12}$ multi-shells systems, where $i=u$ for gold (Au) and $i=g$ for silver (Ag). The $\mathrm{Au}-\mathrm{Au}, \mathrm{Ag}-\mathrm{Ag}, \mathrm{C}-\mathrm{Au}$ and $\mathrm{C}-\mathrm{Ag}$ bond-lengths have been symbolized as $\mathrm{A} i-\mathrm{A} j$ and $\mathrm{C}-\mathrm{A} i, j$, respectively.

\begin{tabular}{|c|c|c|c|c|c|c|}
\hline System & $\operatorname{radii}[\AA]$ & $\mathrm{A} i-\mathrm{A} j[\AA]$ & $\mathrm{C}-\mathrm{C}[\AA]$ & $\mathrm{C}-\mathrm{A} i, j[\AA]$ & Diameter $[\AA]$ & Chiral Index $(\%)$ \\
\hline$I-\mathrm{Au}_{60}$ & $I-\mathrm{Au}_{60}: 5.90$ & $\begin{array}{l}2.70 \triangle \\
2.74 \triangle \\
2.79 \triangle\end{array}$ & $\begin{array}{l}- \\
- \\
-\end{array}$ & $\begin{array}{l}- \\
- \\
-\end{array}$ & 11.78 & 9.10 \\
\hline$I-\mathrm{Ag}_{60}$ & $I-\mathrm{Ag}_{60}: 6.13$ & $\begin{array}{l}2.82 \triangle \\
2.86 \triangle \\
2.88 \triangle\end{array}$ & $\begin{array}{l}- \\
- \\
-\end{array}$ & $\begin{array}{l}- \\
- \\
-\end{array}$ & 12.21 & 8.92 \\
\hline$I-\mathrm{Au}_{72}$ & $\begin{array}{c}I-\mathrm{Au}_{60}: 6.03 \\
I_{h}-\mathrm{Au}_{12}: 6.86\end{array}$ & $\begin{array}{l}2.75 \square \\
2.76 \triangle \\
2.77 \square \\
2.83 \square\end{array}$ & $\begin{array}{l}- \\
- \\
- \\
-\end{array}$ & $\begin{array}{l}- \\
- \\
- \\
-\end{array}$ & 13.71 & 7.9 \\
\hline$I_{h}-\mathrm{C}_{60}$ & $I_{h}-\mathrm{C}_{60}: 3.65$ & - & $\begin{array}{l}1.43 \\
1.49\end{array}$ & - & 7.3 & 0.29 \\
\hline$D_{5}-\mathrm{C}_{60} @ \mathrm{Au}_{60}$ & $\begin{array}{c}I_{h}-\mathrm{C}_{60}: 3.60 \\
I-\mathrm{Au}_{60}: 6.12-6.25\end{array}$ & $2.81-2.92$ & $1.43-1.48$ & $2.51-2.97$ & 12.43 & 10.10 \\
\hline$D_{5}-\mathrm{C}_{60} @ \mathrm{Ag}_{60}$ & $\begin{array}{c}I_{h}-\mathrm{C}_{60}: 3.57 \\
I-\mathrm{Ag}_{60}: 6.27-6.49\end{array}$ & $2.91-3.01$ & $\begin{array}{l}1.42 \\
1.45 \\
\end{array}$ & $2.74-3.24$ & 12.93 & 9.61 \\
\hline$I_{h}-\mathrm{Au}_{32}$ & $\begin{array}{c}I_{h}-\mathrm{Au}_{20}: 3.97 \text { (20-atom dodecahedron) } \\
I_{h}-\mathrm{Au}_{12}: 4.50 \text { (12 stellating atoms) }\end{array}$ & $\begin{array}{l}2.76 \\
2.83 \\
\end{array}$ & $\begin{array}{l}- \\
-\end{array}$ & - & 9.01 & 0.01 \\
\hline$I_{h}-\mathrm{Ag}_{32}$ & $\begin{array}{l}I_{h}-\mathrm{Ag}_{20}: 4.10 \\
I_{h}-\mathrm{Ag}_{12}: 4.66\end{array}$ & $\begin{array}{l}2.85 \\
2.93\end{array}$ & - & - & 9.32 & 0.01 \\
\hline $\mathrm{I}-\mathrm{Au}_{32} @ \mathrm{Au}_{60}^{2+}$ & $\begin{aligned} I_{h}-\mathrm{Au}_{20} & : 3.80 \\
I_{h}-\mathrm{Au}_{12} & : 4.78 \\
I-\mathrm{Au}_{60}: & : 39\end{aligned}$ & $\begin{array}{l}I-\mathrm{Au}_{60}: \\
3.03 \triangle \\
2.83 \triangle \\
2.92 \triangle\end{array}$ & $\begin{array}{l}- \\
- \\
- \\
-\end{array}$ & $\begin{array}{l}- \\
- \\
- \\
-\end{array}$ & 12.72 & 9.91 \\
\hline & & $\begin{array}{c}I_{h}-\mathrm{Au}_{32}: \\
2.71 \\
2.90 \\
\end{array}$ & $\begin{array}{l}- \\
- \\
-\end{array}$ & $\begin{array}{l}- \\
- \\
-\end{array}$ & & \\
\hline$I-\mathrm{Ag}_{32} @ \mathrm{Ag}_{60}^{2+}$ & $\begin{aligned} I_{h}-\mathrm{Ag}_{20} & : 3.98 \\
I_{h}-\mathrm{Ag}_{12} & : 4.87 \\
I-\mathrm{Ag}_{60} & : 6.56\end{aligned}$ & $\begin{array}{l}I-\mathrm{Ag}_{60}: \\
3.03 \triangle \\
2.83 \triangle \\
2.92 \triangle\end{array}$ & $\begin{array}{l}- \\
- \\
- \\
-\end{array}$ & $\begin{array}{l}- \\
- \\
- \\
-\end{array}$ & 13.06 & 9.72 \\
\hline & & $\begin{array}{c}I_{h}-\mathrm{Ag}_{32}: \\
2.84 \\
2.96\end{array}$ & $\begin{array}{l}- \\
- \\
-\end{array}$ & $\begin{array}{l}- \\
- \\
-\end{array}$ & & \\
\hline & & $\begin{array}{c}\mathrm{Ag}_{32}-\mathrm{Ag}_{60}: \\
2.87\end{array}$ & $\begin{array}{l}- \\
-\end{array}$ & $\begin{array}{l}- \\
-\end{array}$ & & \\
\hline$C_{5}-\mathrm{Au}_{60}(\mathrm{MgCp})_{12}$ & $\begin{array}{c}I-\mathrm{Au}_{60}: 5.94 \\
I_{h}-\mathrm{Mg}: 7.14 \\
C_{5 v}-\mathrm{C}: 9.32-9.38 \\
C_{5}-\mathrm{H}: 9.57-9.67\end{array}$ & $\begin{array}{l}I-\mathrm{Au}_{60}: \\
2.73 \triangle \\
2.77 \triangle \\
2.79 \triangle \\
\end{array}$ & $\begin{array}{l}- \\
- \\
- \\
-\end{array}$ & $\begin{array}{l}- \\
- \\
- \\
-\end{array}$ & 11.83 & 7.68 \\
\hline$C_{5}-\mathrm{Ag}_{60}(\mathrm{MgCp})_{12}$ & $\begin{array}{c}I-\mathrm{Ag}_{60}: 6.18 \\
I_{h}-\mathrm{Mg}: 7.38 \\
C_{5 v}-\mathrm{C}: 9.57-9.63 \\
C_{5}-\mathrm{H}: 9.81-9.92\end{array}$ & $\begin{array}{l}I-\mathrm{Ag}_{60}: \\
2.85 \square \\
2.88 \triangle \\
-\end{array}$ & $\begin{array}{l}- \\
- \\
- \\
-\end{array}$ & $\begin{array}{l}- \\
- \\
- \\
-\end{array}$ & 12.31 & 7.46 \\
\hline
\end{tabular}



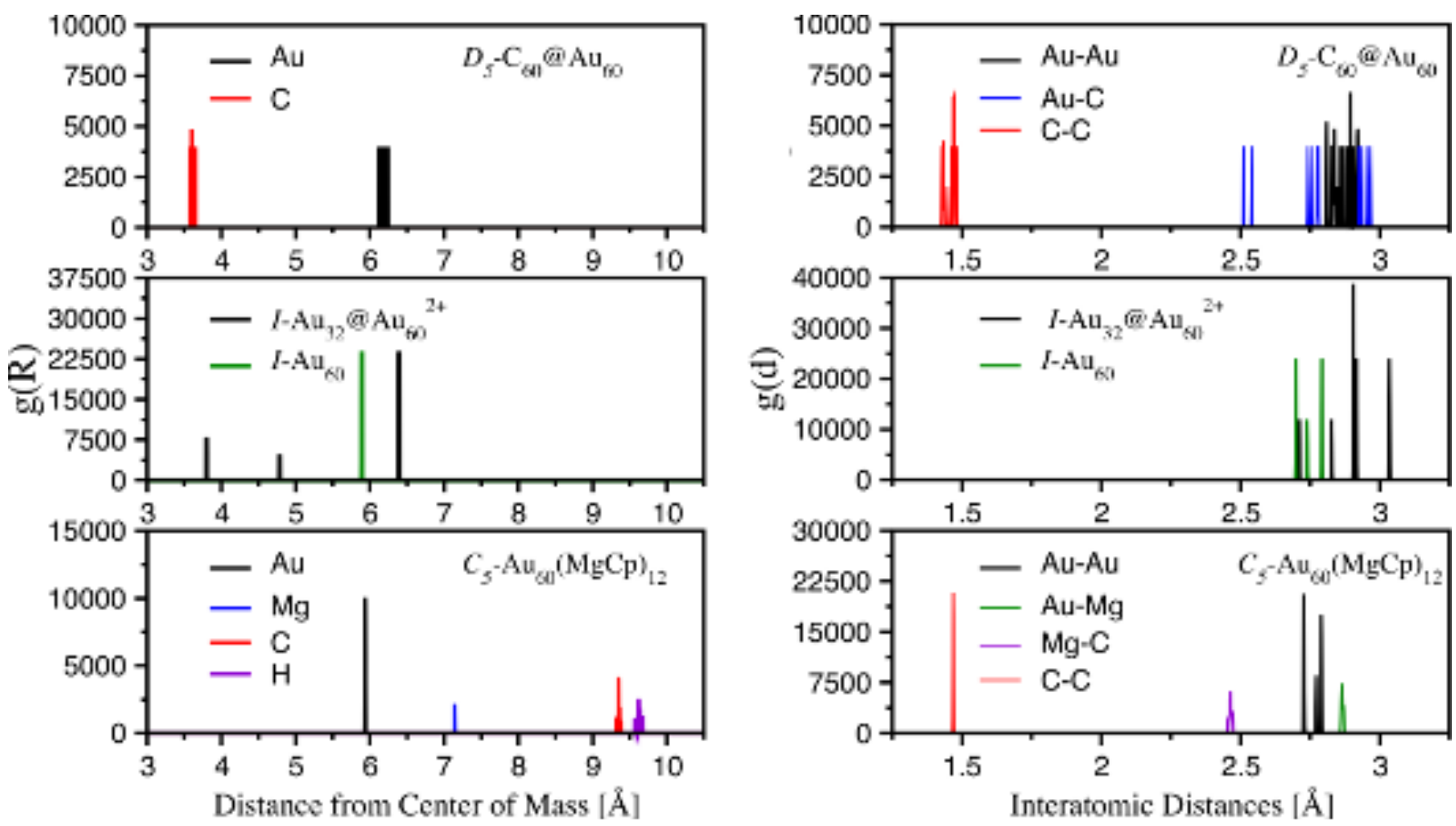

FIG. 3. (left) Radial distribution functions and (right) interatomic distances of the optimized $D_{5}-\mathrm{C}_{60} @ \mathrm{Au}_{60}, I-\mathrm{Au}_{60}, I-\mathrm{Au}_{32} @ \mathrm{Au}_{60}^{2+}$, and $C_{5}-\mathrm{Au}_{60}(\mathrm{MgCp})_{12}$ cluster-structures.
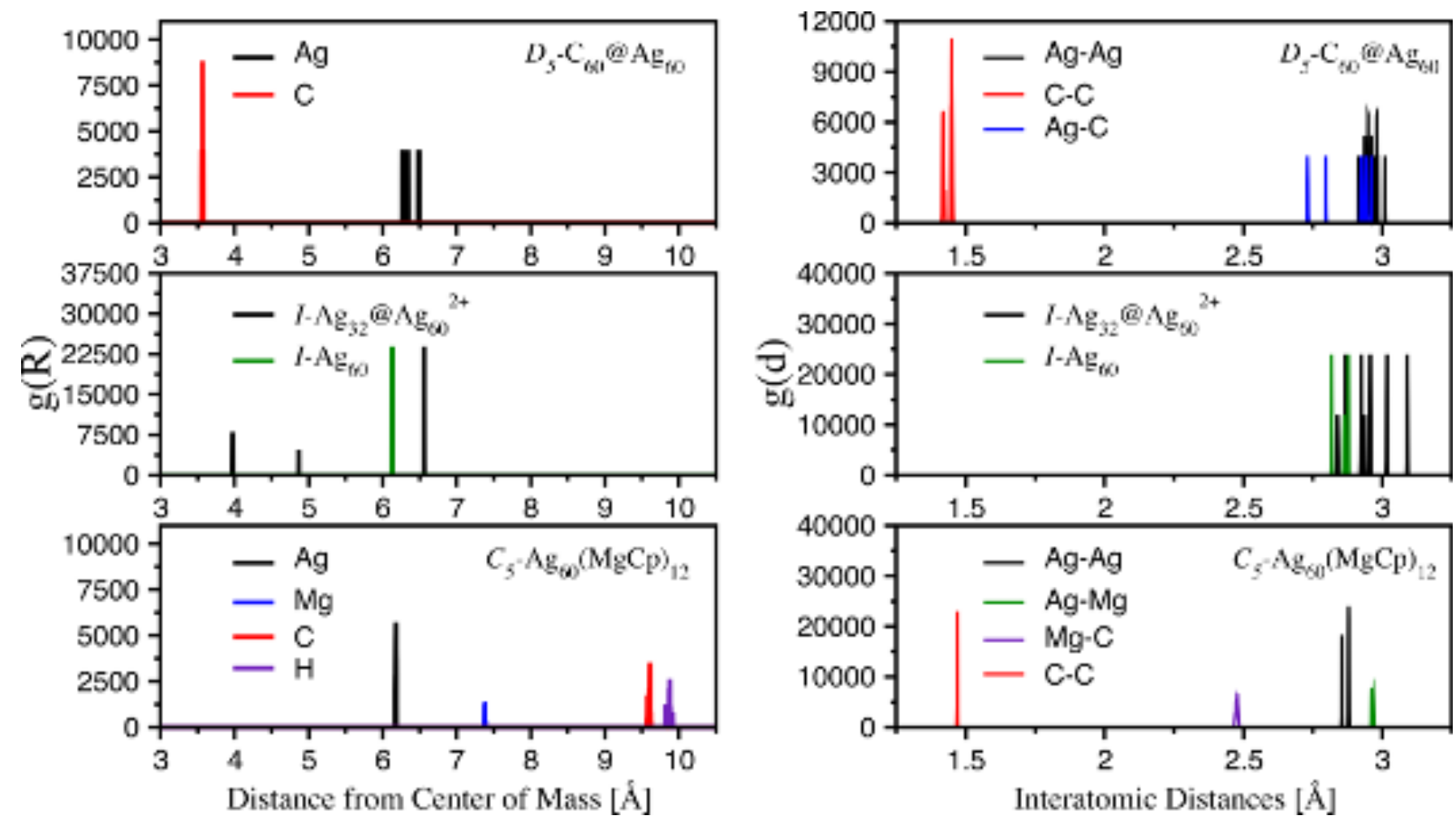

FIG. 4. (left) Radial distribution functions and (right) interatomic distances of the optimized $D_{5}-\mathrm{C}_{60} @ \mathrm{Ag}_{60}, I-\mathrm{Ag}_{60}, I-\mathrm{Ag}_{32} @ \mathrm{Ag}_{60}^{2+}$, and $C_{5}-\mathrm{Ag}_{60}(\mathrm{MgCp})_{12}$. 


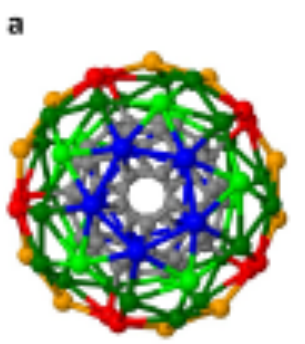

$D_{5}-C_{00}$ aten

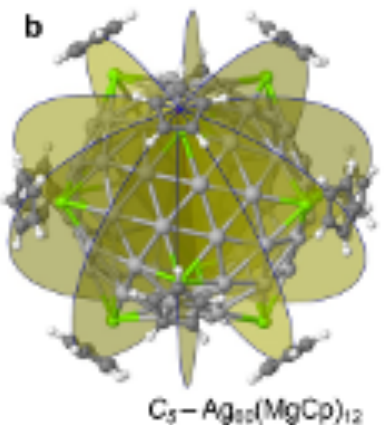

FIG. 5. Symmetry representations of the (a) $D_{5}-\mathrm{C}_{60} @ \mathrm{Au}_{60}$ and (b) $C_{5}-\mathrm{Au}_{60}(\mathrm{MgCp})_{12}$.

interatomic distances remain highly uniform as well, however there is an increase in the $\mathrm{Au}-\mathrm{Au}$ bonds along the pentagons $\checkmark$ from $2.70 \AA$ to $2.73 \AA$ and the $\mathrm{Au}-\mathrm{Au}$ bonds along the triangles become more regular going from $2.74 \AA(\triangle)$ and $2.79 \AA(\triangle)$ in the isolated $I-\mathrm{Au}_{60}$ shell to $2.77 \AA$ and $2.79 \AA$. The $C_{5}-\mathrm{Au}_{60}(\mathrm{MgCp})_{12}$ also has three other radii with $\mathrm{Mg}$ at $7.14 \AA$, C between $9.32-9.38 \AA$, and $\mathrm{H}$ between $9.57-9.67$ $\AA$.

\section{I-Ag 60 -Based Multi-shells}

(iv) $I_{h}-\mathrm{C}_{60} @ I-\mathrm{Ag}_{60}$. Figure 2(d) shows the resulting optimized structure obtained after the relaxation of the initial geometric configuration $I_{h}-\mathrm{C}_{60} @ I-\mathrm{Ag}_{60}$. This system has $D_{5}$ symmetry also (same as for the Au case). The final relaxed structure $D_{5}-\mathrm{C}_{60} @ \mathrm{Ag}_{60}$ is composed of two shells whose symmetry is the same when they are isolated, i.e., the $I_{h}-\mathrm{C}_{60}$ core and the $I-\mathrm{Ag}_{60}$ surrounding it. Similarly to the Au version, the radius of the $\mathrm{C}_{60}$ core compresses $\sim 2 \%$ from $3.65 \AA$ to approximately $3.57 \AA$. The isolated $I-\mathrm{Ag}_{60}$ shell is highly spherical with all atoms located at $6.13 \AA$ from the center of mass. The $\mathrm{Ag}$ shell in the $D_{5}-\mathrm{C}_{60} @ \mathrm{Ag}_{60}$ system is less spherical, of radius expanded $\sim 4 \%$ from 6.13 to $6.38 \pm 0.11 \AA$.

The $\mathrm{Ag}-\mathrm{Ag}$ distances increase and become less regular than in the isolated shell, with bond-lengths ranging from $2.91 \AA$ to $3.01 \AA$, while the $\mathrm{C}-\mathrm{C}$ bond-lengths of the $\mathrm{C}_{60}$ core are likewise contracted to $1.42 \AA$ and $1.45 \AA$. In the isolated $I_{h}-\mathrm{C}_{60}$ and $I-\mathrm{Ag}_{60}$ the radial and interatomic distances are highly uniform, associated with the structures' truncated icosahedron and snub dodecahedron morphologies, respectively. This uniformity appears to decrease in the $D_{5}-$ $\mathrm{C}_{60} @ \mathrm{Ag}_{60}$ system for the $\mathrm{C}_{60}$ and $\mathrm{Ag}_{60}$ shells. The $\mathrm{C}-\mathrm{Ag}$ distances are more ordered, however. A unique bonding pattern can be seen in the $\mathrm{C}-\mathrm{Ag}$ distances, which range from 2.74 - 3.24 A, this is similar as the one presented for Au [Fig. 5(a)].

(v) $I_{h}-\mathrm{Ag}_{32} @ I-\mathrm{Ag}_{60}^{2+}$. The initial geometry $I_{h}-\mathrm{Ag}_{32} @ I-$ $\mathrm{Ag}_{60}^{2+}$ structure exhibits three radii, of approximately $3.98 \AA$, $4.87 \AA$, and $6.56 \AA$, in the ratio 20:12:60. Figure 2(e) shows the optimized $I_{h}-\mathrm{Ag}_{32} @ I-\mathrm{Ag}_{60}^{2+}$ structure after the atomic relaxation. Similarly to the Au version, the relaxed core-shell structure has (icosahedral) I-symmetry. Once more we observe a decrease in the radius of the 20 -atom dodecahedron in the $\mathrm{Ag}_{32}$, an increase in radius of the 12 atoms stellating the pentagons in $\mathrm{Ag}_{32}$ (now between the shells), as well as an expansion of the outermost $\mathrm{Ag}_{60}$. The three characteristic $\mathrm{Ag}-\mathrm{Ag}$ bond-lengths in the $\mathrm{I}_{-\mathrm{Ag}_{60}}[2.82 \AA(\triangle), 2.86 \AA$ $(\triangle)$, and $2.88 \AA(\triangle)]$ become $3.03 \AA, 2.83 \AA$, and $2.92 \AA$, respectively, in the relaxed $I-\mathrm{Ag}_{32} @ \mathrm{Ag}_{60}^{2+}$ system. There are three other $\mathrm{Ag}-\mathrm{Ag}$ bond-lengths of $2.84 \AA$ and $2.96 \AA$ in the $\mathrm{Ag}_{32}$, and bonds of $2.87 \AA$ between the $\mathrm{Ag}_{32}$ and $\mathrm{Ag}_{60}$ shells.

(vi) $I-\mathrm{Ag}_{60}(\mathrm{MgCp})_{12}$. After structural optimization of the initial geometric configuration $I-\mathrm{Ag}_{60}(\mathrm{MgCp})_{12}$, we found the relaxed structure shown in Figure 2(f). This system has also $C_{5}$-symmetry as its analog in Au. The $C_{5}-\mathrm{Ag}_{60}(\mathrm{MgCp})_{12}$ has four radii with the $\mathrm{Ag}_{60}$ shell at $6.18 \AA, \mathrm{Mg}$ at $7.38 \AA$, C between $9.57-9.63 \AA$, and $\mathrm{H}$ between $9.81-9.92 \AA$. Once again the $\operatorname{Ag}_{60}\left(\mathrm{MgCp}_{12}\right.$ structure best preserves the isolated $\mathrm{Ag}_{60}$ shell with a $0.8 \%$ increase in radius. However, where the $I-\mathrm{Ag}_{60}$ had three unique $\mathrm{Ag}-\mathrm{Ag}$ bond-lengths $[2.82 \AA(\triangle), 2.86 \AA(\triangle)$, and $2.88 \AA(\triangle)]$, the $\operatorname{Ag}_{60}(\mathrm{MgCp})_{12}$ bonds become more uniform with only two bond-lengths of $2.85 \AA(\triangle)$ and 2.88 $\AA(\triangle)$. The initial symmetry calculation of the optimized $\mathrm{A} i_{60}(\mathrm{MgCp})_{12}$ systems gave the low symmetry result of $C_{5}$, however their highly degenerate electronic states (see Figs. 6 and 7) indicated a higher icosahedral symmetry. The Jmol tool analyzes the atomic position for symmetry and allows a default tolerance of $0.2 \AA$ from symmetry equivalent sites. Analyzing the $\mathrm{Au}(\mathrm{Ag})$ and $\mathrm{Mg}$ atoms we calculated $I$ and $I_{h}$ symmetries, respectively. The overall low symmetry results of $C_{5}$ come from the $\mathrm{C}$ and $\mathrm{H}$ atoms with $C_{5 v}$ and $C_{5}$, respectively. This may be due to the lack of symmetrization of the initial structure model however. We were able to observe the expected $I$-symmetry by loosening the symmetry tolerances in $\mathrm{Jmol}^{30}$ to $0.8 \AA$. Figure 5 (b) shows the drawing of symmetry planes in the $C_{5}-\mathrm{Au}_{60}(\mathrm{MgCp})_{12}$ using the Jmol software.

\section{Hausdorff Chirality Measure}

Chirality is a rare feature of high-symmetry nanoclusters. One example of a chiral structure is the $\mathrm{Au}_{72}$ shell structure ${ }^{5}$. $\mathrm{Au}_{72}$ is a hollow cage structure theoretically predicted from geometric principles. The $\mathrm{Au}_{72}$ structure is viewed as a combination of a 12-atom icosahedron and a 60 -atom snub dodecahedron. The regular icosahedron is achiral with full icosahedral symmetry whereas the snub dodecahedron has chiral icosahedral symmetry. The $\mathrm{Au}_{72}$ had been the smallest theoretically predicted molecule of chiral icosahedral symmetry, although it has been shown to be very stable relative to similar $\mathrm{Au}$ cages such as the $\mathrm{Au}_{18}, \mathrm{Au}_{32}, \mathrm{Au}_{42}$, and $\mathrm{Au}_{50}$.

We have previously emphasized that "The profound chirality discovered in the $I-\mathrm{Au}_{60}$ has significant implications for its electronic and optical properties. The achiral $I_{h^{-}}$ 
$\mathrm{Au}_{60}$ shell, an (3.4.5.4)-polyhedron, spontaneously transforms into a quite distinct $I-\mathrm{Au}_{60}$ structure, an $\sim$ (3.3.3.5)polyhedron, in which any small fluctuation determines which one of the two enantiomeric forms results. For this reason, the process is termed a chiral (icosahedral) symmetry breaking, although the chirality is generated, rather than destroyed in the transition. (The symmetry-elements destroyed are rather the unique inversion-center and manifold reflection planes.) From a purely geometrical standpoint, this transition may be regarded as a simple one, since if one assumes fixed edge-lengths (bond-distances): the resulting structure is not only more compact but more spherical, and of course the coordination-number at each site also increase". ${ }^{3}$ Whether this unique chiral characteristic is preserved in the core-shell structures is of great interest. To this end, we calculated the chirality of the multi-shell structures through the Hausdorff Chirality Measure $(\mathrm{HCM})^{36}$. The chiral index, expressed as a percentage of the diameter, as well as the diameter of the respective $\mathrm{Au}_{60}$ shell is given in Table $\mathrm{I}$.

The HCM of $I-\mathrm{Au}_{60}, I_{h}-\mathrm{C}_{60}$, and $I_{h}-\mathrm{Au}_{32}$ are 0.091 , 0.003 , and 0 , i.e., $9.10,0.29$, and $0.00 \%$ of diameter, respectively. The HCM of $D_{5}-\mathrm{C}_{60} @ \mathrm{Au}_{60}, I-\mathrm{Au}_{32} @ \mathrm{Au}_{60}^{2+}$, and $C_{5}-\mathrm{Au}_{60}(\mathrm{MgCp})_{12}$ clusters are $0.101,0.0991$, and 0.0768 , respectively, i.e., 10.1, 9.91, and $7.68 \%$ of diameter. The $D_{5-}$ $\mathrm{C}_{60} @ \mathrm{Au}_{60}$ has the highest chiral index of all structures investigated here, also equals to the chiral index of the ideal [3.3.3.3.5*] snub dodecahedron. The Ag structures have lower chiral indices, in part due to the larger diameters. The HCM of $I-\mathrm{Ag}_{60}$ and $I_{h}-\mathrm{Ag}_{32}$ are 0.0892 and 0 , or 8.92 and $0.01 \%$ of the diameter. For the Ag-based multishells, the HCM of $D_{5}-\mathrm{C}_{60} @ \mathrm{Ag}_{60}, I-\mathrm{Ag}_{32} @ \mathrm{Ag}_{60}^{2+}$, and $C_{5}-$ $\mathrm{Ag}_{60}(\mathrm{MgCp})_{12}$ clusters are 0.0972, 0.0961, and 0.0746, respectively, i.e., 9.61, 9.72 and $7.46 \%$ of diameter. These values indicate that, despite increases in diameter, the introduction of a $\mathrm{C}_{60}, \mathrm{Au}_{32}$, or $\mathrm{Ag}_{32}$ core is accompanied by an increase of the HCM index of chirality. We see that for the cases of the ligand protected $\operatorname{Ag}_{60}(\mathrm{MgCp})_{12}$ there is also a slight increase in the chirality of the $\mathrm{Ag}_{60}$ shell with respect to the isolated $I-\mathrm{Ag}_{60}$ from $8.92 \%$ to $8.99 \%$, even while the diameter increases. For the $\mathrm{Au}_{60}(\mathrm{MgCp})_{12}$ there is actually a slight decrease in chirality of the $\mathrm{Au}_{60}$ shell with respect to the isolated $I-\mathrm{Au}_{60}$ from $9.10 \%$ to $8.97 \%$ associated with the increase in diameter.

\section{ELECTRONIC ANALYSIS - DENSITY OF STATES}

The exceptional symmetry and chirality present in the $I-\mathrm{Au}_{60}$ manifests in highly discrete and degenerate electronic states, as evidenced in the calculated electronic density of states (eDOS). Here, we present the eDOS of the $I_{h}-\mathrm{C}_{60} @ I-$ $\mathrm{A} i_{60}, I_{h}-\mathrm{A} i_{32} @ I-\mathrm{A} i_{60}^{2+}$ bilayer structure and $I-\mathrm{A} i_{60}(\mathrm{MgCp})_{12}$ clusters, see Fig. 6 and Fig. 7. To highlight both the general shape and the discreteness of the eDOS, we draw the eDOS convoluted with Lorentzians of different width, viz., with $\sigma$ $=0.1$ (black) and $0.01 \mathrm{eV}$ (red). The zero energy in Fig. 6 corresponds to the HOMO energy state and degeneracies are

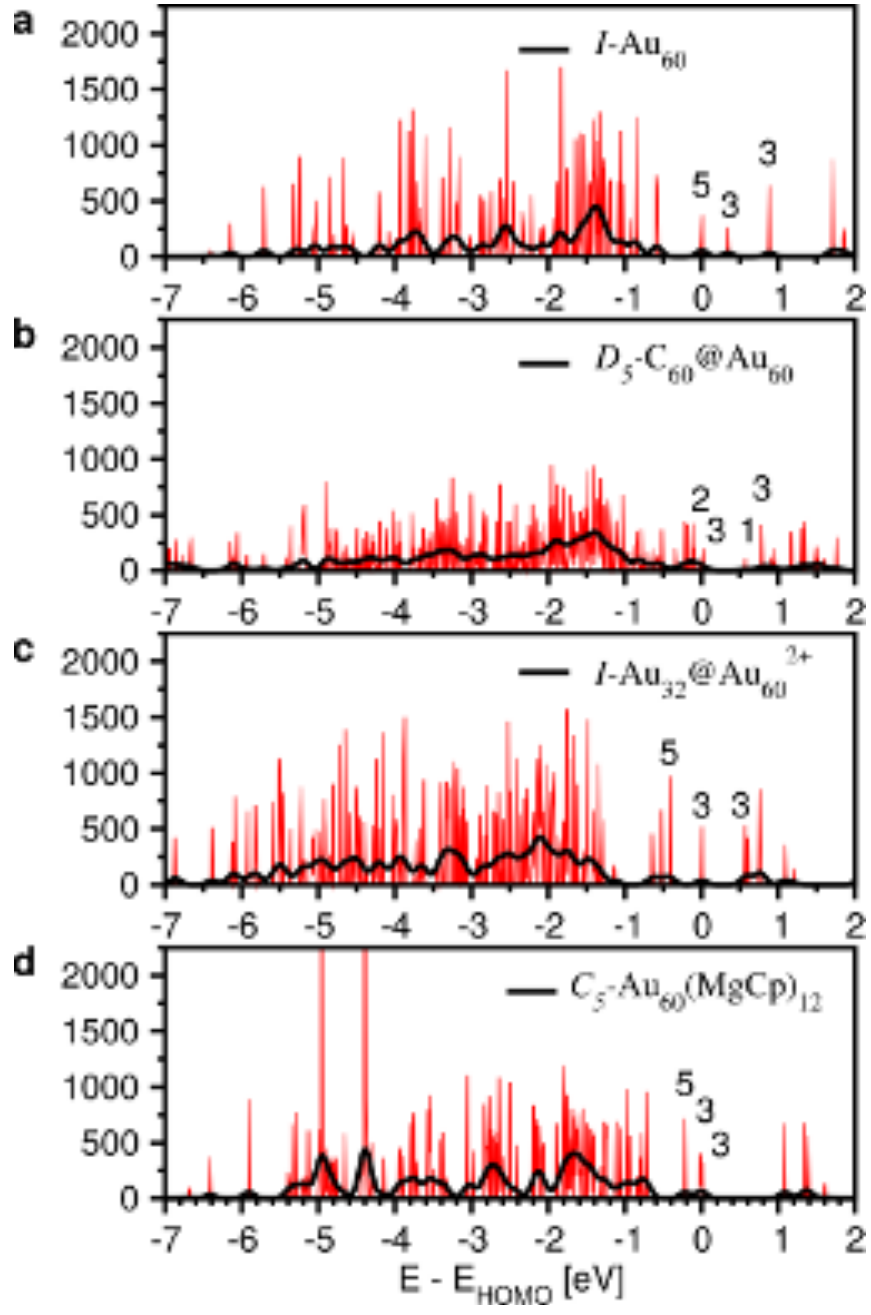

FIG. 6. Electronic density of states (eDOS) of the (a) $I-\mathrm{Au}_{60}$, (b) $D_{5}-$ $\mathrm{C}_{60} @ \mathrm{Au}_{60}$, (c) $I-\mathrm{Au}_{32} @ \mathrm{Au}_{60}^{2+}$, and (d) $C_{5}-\mathrm{Au}_{60}(\mathrm{MgCp})_{12}$ clusters.

indicated by the numeral labels.

\section{Au-Based Multi-shells}

(i) $I_{h}-\mathrm{C}_{60} @ I-\mathrm{Au}_{60}$. The eDOS of the $D_{5}-\mathrm{C}_{60} @ \mathrm{Au}_{60}$, by contrast to the other core-shell structures, displays a more smeared lineshape characteristic of low-symmetry clusters in this size -range $e^{21}$. Still some degeneracies are found in the order of $2-3-1-3$ at $-0.09 \mathrm{eV}, 0 \mathrm{eV}, 0.57 \mathrm{eV}$, and $0.78 \mathrm{eV}$.

(ii) $I_{h}-\mathrm{Au}_{32} @ I-\mathrm{Au}_{60}^{2+} . \quad$ The high degeneracies shown in the eDOS of the $I-\mathrm{Au}_{60}$ and $I_{h}-\mathrm{Au}_{32} @ I-\mathrm{Au}_{60}^{2+}$ clusters reflect the structures' icosahedral symmetry. The $I-\mathrm{Au}_{60}$ and $I_{h}-\mathrm{Au}_{32} @ I-\mathrm{Au}_{60}^{2+}$ both have degenerate energy states in the order of $5-3-3$ with energies of $0 \mathrm{eV}, 0.35 \mathrm{eV}$, and 0.88 $\mathrm{eV}$ for the $\mathrm{I}-\mathrm{Au}_{60}$ and $-0.41 \mathrm{eV}, 0 \mathrm{eV}$, and $0.57 \mathrm{eV}$ for the $I_{h}-\mathrm{Au}_{32} @ I-\mathrm{Au}_{60}^{2+}$.

(iii) $I-\mathrm{Au}_{60}(\mathrm{MgCp})_{12}$. Although the $\mathrm{Au}_{60}(\mathrm{MgCp})_{12}$ is cal- 
culated to have a $C_{5}$ symmetry, degenerate energy states are present and the icosahedral 5-3-3 ordering of the states also appears at $-0.22 \mathrm{eV},-0.02 \mathrm{eV}$, and $0 \mathrm{eV}$, i.e the states are fully occupied. The discrepancy between the presence of highly degenerate electronic states and the calculated symmetry of $C_{5}$ may be due to the fact that the deviation from the $I$-symmetry is small enough not to substantially lift the degeneracy of the electronic states but large enough to break the symmetry for the given JMOL tolerance. The calculated HOMO-LUMO gap of the $I-\mathrm{Au}_{60}, D_{5}-\mathrm{C}_{60} @ \mathrm{Au}_{60}, I-\mathrm{Au}_{32} @ \mathrm{Au}_{60}^{2+}$, and $C_{5^{-}}$ $\mathrm{Au}_{60}(\mathrm{MgCp})_{12}$ clusters are 0.33, 0.56, 0.57, and $1.08 \mathrm{eV}$, respectively, which is comparable with similar stable gold clusters.

\section{Ag-Based Multi-shells}

The electronic density of states (eDOS) of the $I-\mathrm{Ag}_{60}$, $D_{5}-\mathrm{C}_{60} @ \mathrm{Ag}_{60}, \quad I-\mathrm{Ag}_{32} @ \mathrm{Ag}_{60}^{2+}, \quad$ and $C_{5}-\mathrm{Ag}_{60}(\mathrm{MgCp})_{12}$ clusters is shown in Fig. 7. Overall, the Ag shells exhibit a larger number of degenerate orbital levels which penetrate deeper below the Fermi Energy with respect to the Au shells.

(iv) $I_{h}-\mathrm{C}_{60} @ I-\mathrm{Ag}_{60} . \quad$ The eDOS of the $D_{5}-\mathrm{C}_{60} @ \mathrm{Ag}_{60}$ again displays a more smeared lineshape although degeneracies are still present. The level ordering in the $D_{5}-\mathrm{C}_{60} @ \mathrm{Ag}_{60}$ near the Fermi energy is $4-1-1-2$ with states at $-0.02 \mathrm{eV}$, $0 \mathrm{eV}, 0.45 \mathrm{eV}$, and $0.54 \mathrm{eV}$, respectively.

(v) $I_{h}-\mathrm{Ag}_{32} @ I-\mathrm{Ag}_{60}^{2+}$. The icosahedral symmetry of the $I-\mathrm{Ag}_{60}$ and $I_{h}-\mathrm{Ag}_{32} @ I-\mathrm{Ag}_{60}^{2+}$ clusters are reflected by highly degenerate orbitals. The $I-\mathrm{Ag}_{60}$ shows the familiar 5-3-3 icosahedral energy state pattern at $0 \mathrm{eV}, 0.08 \mathrm{eV}$, and $0.55 \mathrm{eV}$. The $I_{h}-\mathrm{Ag}_{32} @ I-\mathrm{Ag}_{60}^{2+}$ is similar but with a $5-3-4$ pattern at $-0.24 \mathrm{eV}, 0 \mathrm{eV}$, and $0.72 \mathrm{eV}$.

(vi) $I-\mathrm{Ag}_{60}(\mathrm{MgCp})_{12}$. Similar to the $\mathrm{Au}_{60}(\mathrm{MgCp})_{12}$, the $\operatorname{Ag}_{60}(\mathrm{MgCp})_{12}$ is calculated to have a $C_{5}$ symmetry and highly degenerate energy states occur. However, the icosahedral $5-3-3$ ordering of the states present in the $I-\mathrm{Ag}_{60}$ is not present in the $\mathrm{Ag}_{60}(\mathrm{MgCp})_{12}$ and is instead reversed $(3-3-5)$ at $-0.33 \mathrm{eV},-0.09 \mathrm{eV}$, and $0 \mathrm{eV}$.

The calculated HOMO-LUMO gap of the $I-\mathrm{Ag}_{60}, D_{5^{-}}$ $\mathrm{C}_{60} @ \mathrm{Ag}_{60}, I-\mathrm{Ag}_{32} @ \mathrm{Ag}_{60}^{2+}$, and $C_{5}-\mathrm{Ag}_{60}(\mathrm{MgCp})_{12}$ clusters are $0.10,0.45,0.72$ and $0.51 \mathrm{eV}$, respectively. The HOMOLUMO gap for each of the Ag structures are smaller than their Au counterparts in all but the $I-\mathrm{Ag}_{32} @ \mathrm{Ag}_{60}^{2+}$.

The $I-\mathrm{Au}_{32} @ \mathrm{Au}_{60}^{2+}$ and $I-\mathrm{Ag}_{32} @ \mathrm{Ag}_{60}^{2+}$ have 92 valence electrons in the neutral state with each $\mathrm{Au} / \mathrm{Ag}$ atom contributing one electron to the valency. This corresponds to an electronic shell closing in the superatom complex model. ${ }^{20}$ The charge-state [2+] was selected to obtain a large HOMOLUMO gap (0.57 for $\mathrm{Au}_{32} @ \mathrm{Au}_{60}^{2+}$ and 0.72 for $\mathrm{Ag}_{32} @ \mathrm{Ag}_{60}^{2+}$ ) that occurs with hollow bilayer structures and a free-electron count of $90^{34}$. The degeneracy and level-ordering of the frontier orbitals also agrees well with the work of Chakraborty

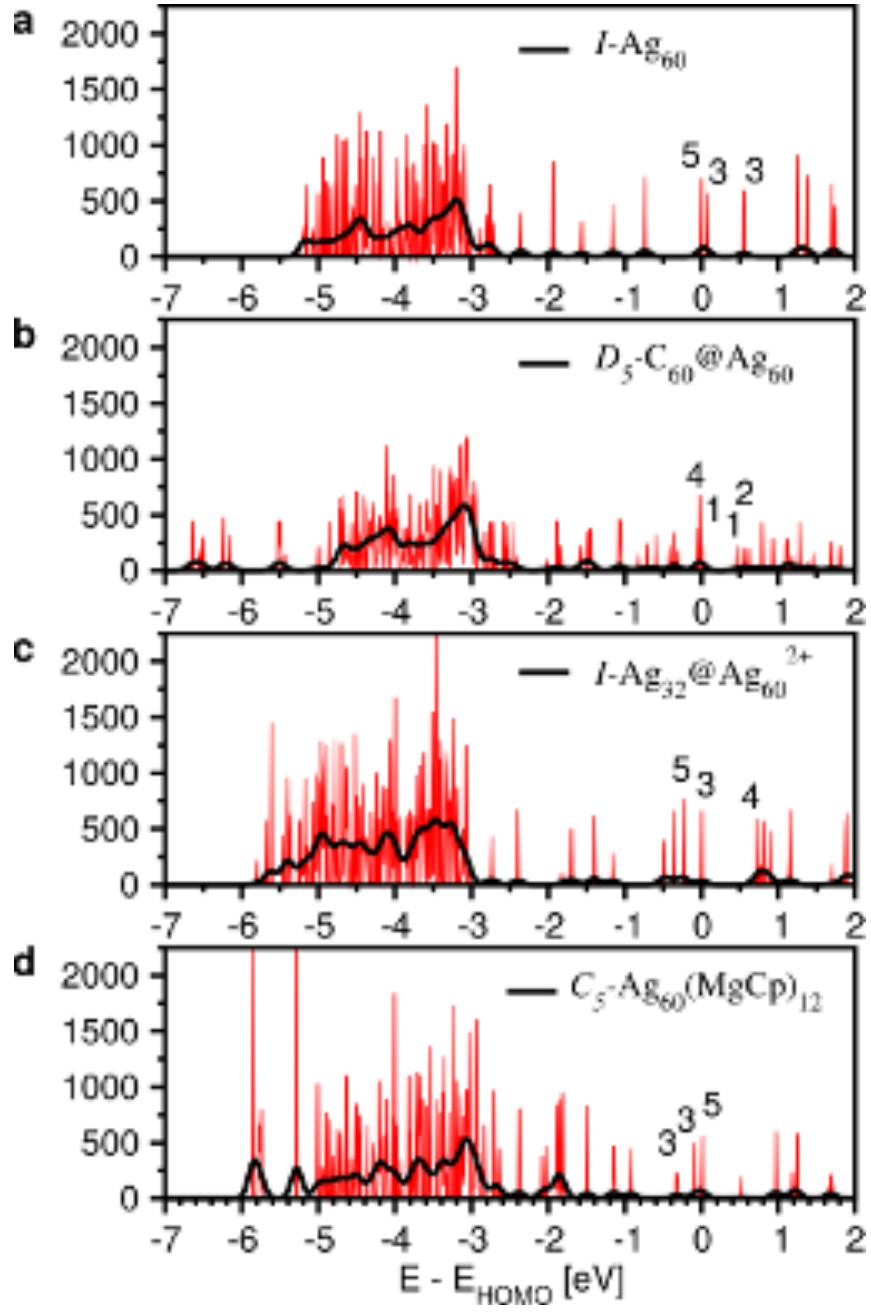

FIG. 7. Electronic density of states (eDOS) of the (a) $I-\mathrm{Ag}_{60}$, (b) $D_{5}$ $\mathrm{C}_{60} @ \mathrm{Ag}_{60}$, (c) $I-\mathrm{Ag}_{32} @ \mathrm{Ag}_{60}^{2+}$, and (d) $C_{5}-\mathrm{Ag}_{60}(\mathrm{MgCp})_{12}$ clusters.

et al. ${ }^{34}$ With respect to the electronic shell structure of the $\mathrm{Au}_{60}(\mathrm{MgCp})_{12}$ and $\mathrm{Ag}_{60}(\mathrm{MgCp})_{12}, \mathrm{Au} / \mathrm{Ag}$ atoms contribute one valence electron, $\mathrm{Mg}$ contributes two electrons, and each of the $12 \mathrm{Cp}$ ligands withdraws one electron, resulting in a total of 72 valence electrons. This corresponds to a shell closing in hollow monolayer structures ${ }^{5}$ resulting in an increased electronic stability shown by the opening up of a large HOMOLUMO gap of $1.08 \mathrm{eV}$ and $0.51 \mathrm{eV}$ in the $I-\mathrm{Au}_{60}(\mathrm{MgCp})_{12}$ and $I-\mathrm{Ag}_{60}(\mathrm{MgCp})_{12}$, respectively.

\section{DISCUSSION}

In this Report, we have described an exploration of how the chiral-icosahedral golden shell, denoted simply by $\mathrm{I}-\mathrm{Au}_{60}$, may be realized in practice, i.e., the forms in which it may be first detected as produced in natural or synthetic processes. The particular forms used for this investigation were carefully selected to be those in accord with established (chemical) precedent. 
As a consequence, it is hardly surprising that all cases from the three classes of 'augmented' systems - converged smoothly from initial configurations to final stable forms that preserve essential (critical) structural and electronic characteristics of the isolated $I-\mathrm{Au}_{60}{ }^{z-}$ shell.

In addition, we separately generated the silver-for-gold analogs, as a way to determine which characteristics may be unique to the case of quasi-2D gold.

Although all six systems - the pairs of cases from all three classes - are interesting in their own rights, one may offer a critical chemical-physics assessment of the results, as follows: 1. The best result is provided by encapsulation within a shell of 12 one-electron donors, represented herein by the $\mathrm{MgCp}^{+}$ groups, as judged by the following criteria: (i) least strain, i.e., smallest change in the $I-\mathrm{Au}_{60}$ structure, and mainly in the direction of the 60 -atom subshell of the $I-\mathrm{Au}_{72}$ structure previously discussed ${ }^{3}$; (ii) optimal filling of the frontier orbitals (HOMOs/LUMOs), in accordance with the anticipated 'formal charge' of $z=12$ on the $I-\mathrm{Au}_{60}$ 'core'; (iii) largest gap, i.e., HOMO-LUMO separation $>1.0 \mathrm{eV}$, cf., Fig. 6(d), between the top of the well-organized set of (11) L $=5$ HOMOs from the base of the (13) L $=6$ LUMOs, the centers-of-gravity of the two sets being separated by $\approx 1.35 \mathrm{eV}$, nearly equal to the $1.27 \pm 0.04 \mathrm{eV}$ calculated from a naïve electron-on-sphere model, with the sphere radius set at $\approx 6.0 \pm 0.1 \AA$; (iv) exceptional chemical interest motivated by the well-precedented ${ }^{35}$ variability both of the ferrocene-derived electropositive metal $\left(\mathrm{Mg}^{2+}\right)$ cations, e.g., magnetic $\mathrm{Mn}^{2+}$ or $\mathrm{Fe}^{2+}$ could replace them, as well as steric protection offered by a 'canopy' of the (12) $\mathrm{Cp}^{-}$groups, which may here represent also more extensive structures, e.g., enlargement from $\mathrm{C}_{5} \mathrm{H}_{5}$ to $\mathrm{Cp}^{*}=$ $\mathrm{C}_{5}\left(\mathrm{CH}_{3}\right)_{5}$; or even to complete encapsulation by larger chiralicosahedral fullerenes, $I-\mathrm{C}_{140}$ and beyond, that also accept 12 electrons, one at each pentagon.

2. Second best is the $\mathrm{C}_{60} @ \mathrm{Au}_{60}$, which suffers from a much larger strain (structural change in the $I-\mathrm{Au}_{60}$ shell) yet not quite enough to disrupt the Au-Au bonding or frontier energylevel structure. This detrimental strain factor appears to offset the evident appeal of templating on the fullerene $I_{h}-\mathrm{C}_{60}$ 'core', following the tracks laid by the Stuttgart group (T.P. Martin and coworkers) in the 1990s. But then one should also consider what has been learned in (1.) immediately above: From an electrochemical standpoint, the $I_{h}-\mathrm{C}_{60}$ and $I-\mathrm{Au}_{60}$ sub-structures are each 12e deficient. Perhaps, then, the 'intercalation' of 12 small lithium cations $\left(12 \mathrm{Li}^{+}\right)$, one on each carbon $\mathrm{C}_{5}$ pentagon, as in the solid-state electrochemistry of $\mathrm{Li}_{12} \mathrm{C}_{60}$, along with 12 external $\mathrm{MgCp}$ groups, as above, could produce a much more satisfactory outcome, both theoretically and experimentally.

3. Third is the bilayer structure $\mathrm{Au}_{32} @ \mathrm{Au}_{60}$, which involves considerable strain to both shells, as not only the enlargement of the $I-\mathrm{Au}_{60}$ shell, but also the radial displacement of the 12 'stellating' atoms, suggest stronger-than-expected interactions. However, before dismissing this approach, one may consider slight modifications, e.g., (i) substituting $\mathrm{Cu}$-for- $\mathrm{Au}$ in the inner shell (i.e., $\mathrm{Cu}_{32} @ \mathrm{Au}_{60}$ ) to relieve the repulsion that enlarges the $I-\mathrm{Au}_{60}$ shell, as described Ferrando and coworkers ${ }^{37}$, and (ii) adding 12 groups such as, once again, the MgCp-class to satisfy both structural and electronic stabilization of an $I-\mathrm{Au}_{60}\left[12^{-}\right]$shell that is largely unmodified from the freestanding form. Remarkably, a close examination of the Yoon et al. results ${ }^{34}$ - particularly the band of (7) LUMOs of $2 \mathrm{~F}(14)$ character - on the $I-\mathrm{Ag}_{32} @ \mathrm{Ag}_{60}{ }^{2+}$ system indeed suggests that the nested subshells in the $I-\mathrm{A}_{32} @ \mathrm{~A}_{60}^{12-}$ could simultaneous satisfy both the $32 e$ and $72 e$ closings.

Lest these considerations (1.-3.) seem only to appear as suggestions for further, expanded computational theoretical and simulations work, we hasten to add that they rather suggest an experimental program to realize the striking advantages noted previously ${ }^{3}$ for the $I-\mathrm{Au}_{60}$ shell, particularly in its anionic charge states. A deep and enduring motivation for achieving such high-symmetry and hence electronically highly degenerate systems has been described in considerable detail by Kresin and coworkers: the search for higher temperature (even room-temperature) superconductors, as practical materials based on such metallic clusters ${ }^{38}$.

Finally, a word may be added on the utility of the Ag-vs.-Au comparisons as indications of the unique advantages of the latter $(\mathrm{Au})$ for realizing quasi-2D metallic structures, ultimately relating to the extreme $5 d-6 s$ (quadrupolar) hybridization and originating in the similarly extreme relativistic contraction of its atomic core electrons. Here we need not dwell upon the generally greater difficulty of protecting metallic silver from corrosion (oxidation etc.) Rather we are focused on the particular circumstances of the planar (2D) and more especially the curved / closed-net (quasi-2D) structures, and the additional, 'new' evidence that our results provide on the physical (mechanical) as opposed to merely chemical (corrosionresistance) advantages of Au-over-Ag. These are provided mainly by the estimates for the cohesion of the hollow cage or shell structures, with respect to bulk forms (3D, FCC) of the respective elements, wherein the $2 \mathrm{D}$ gold structures (whether infinite-planar or finite curved) attain a surprisingly large fraction of the total cohesion of the bulk, as first noted by Trombach et al. ${ }^{1}$. In addition, there is the quite extraordinary contraction of the $I-\mathrm{Au}_{60}$ interatomic distances in the case of gold but not silver. Clearly, this is a subject of continuing interest for which the highest detective skills may be required.

\section{CONCLUSIONS}

The theoretical investigation of high-stability structures at the nanoscale is fundamental for the continuing development of novel nanomaterials. Compelled by the unique rigidity of the chiral icosahedral 60 -atom $\mathrm{Au}$ shell $\left(I-\mathrm{Au}_{60}\right)^{3}$, our goal is to demonstrate that this shell can be isolated or stabilized through various shells. For this purpose, several core-shell and ligated shell structures are proposed, namely $I_{h}-\mathrm{C}_{60} @ I-$ $\mathrm{Au}_{60}, I_{h}-\mathrm{Au}_{32} @ I-\mathrm{Au}_{60}^{2+}$ as bilayer structures; or by an outer shell, as in $I-\mathrm{Au}_{60}(\mathrm{MgCp})_{12}$, as well as $\mathrm{Ag}$ versions of each structure. First-principles DFT calculations were performed to investigate the structure and electronic stability of these six nanoclusters. Our calculations indicate that the $I-\mathrm{Au}_{60}$ shell 
is quite stable, for the $I$-symmetry is preserved and the shell is slightly deformed only in the case of $I_{h}-\mathrm{C}_{60} @ I-\mathrm{Au}_{60}$ system. Therefore, the $I-\mathrm{Au}_{60}$ shell can be stabilized through different shells. All the structures exhibit highly degenerate energy states near the Fermi energy. These degeneracies can be attributed to the structures' unique, highly symmetric and chiral morphologies. Interestingly, the Ag nanoclusters show an even larger number of profoundly degenerate energy states than the Au clusters. The high degeneracies may be crucial to the search for high-temperature superconductivity in metallic clusters and their coupled arrays. ${ }^{38}$ Our results give further evidence to the unique occurrence and importance of chiral icosahedral nanostructures such as the $I-\mathrm{Au}_{60}$ and its derivatives. This work aims to motivate and provide a guide to the experimental synthesis of these $I-\mathrm{Au}_{60}$ and $I-\mathrm{Au}_{60}$ shellbased nanostructures.

\section{ACKNOWLEDGMENTS}

RLW acknowledges support from the Welch Foundation AX1857. H.C.W. acknowledges support from the French Research Agency (Agence National de Recherche, ANR) in the frame of the project "FIT SPRINGS", ANR-14-CE080009 and HPC resources from GENCI-IDRIS (Grant 2019096829). X.L.L. acknowledges previous funding from NSFDMR-1103730 and NSF-PREM DMR-0934218. This work received computational support from the Laboratory of Computational Nanotechnology (LCNT) and UTSA Research Computing Support Group through the HPC clusters Antares3 and SHAMU, respectively.

\section{DATA AVAILABILITY STATEMENT}

The structure data (atomic coordinates of the optimized structures) that support the findings of this study are available from the corresponding author upon reasonable request.

${ }^{1}$ L. Trombach, S. Rampino, L.-S. Wang, and P. Schwerdtfeger, "Hollow gold cages and their topological relationship to dual fullerenes," Chemistry - A European Journal 22, 8823-8834 (2016), https://chemistryeurope.onlinelibrary.wiley.com/doi/pdf/10.1002/chem.201601239.

${ }^{2}$ S. Yamazoe, K. Koyasu, and T. Tsukuda, "Nonscalable oxidation catalysis of gold clusters," Acc. Chem. Res 47, 816-824 (2014).

${ }_{3}^{3}$ S.-M. Mullins, H.-C. Weissker, R. Sinha-Roy, J. J. Pelayo, I. L. Garzón, R. Whetten, , and X. López-Lozano, "Chiral symmetry breaking yields the $i-\mathrm{au}_{60}$ perfect golden shell of singular rigidity," Nature Communications $\mathbf{9}$, 3352 (2018).

${ }^{4}$ H. Ning, J. Wang, Q.-M. Ma, H.-Y. Han, and Y. Liu, "A series of quasi-icosahedral gold fullerene cages: Structures and stability," Journal of Physics and Chemistry of Solids 75, 696-699 (2014).

${ }^{5}$ A. J. Karttunen, M. Linnolahti, T. A. Pakkanen, and P. Pyykko, "Icosahedral $\mathrm{au}_{72}$ : a predicted chiral and spherically aromatic golden fullerene," Chem. Commun. 4, 465-467 (2008).

${ }^{6}$ M. P. Johansson, D. Sundholm, and J. Vaara, "Au ${ }_{32}$ : A 24-carat golden fullerene," Angewandte Chemie International Edition 43, 26782681 (2004).

${ }^{7}$ S. N. Khanna and P. Jena, "Assembling crystals from clusters," Phys. Rev. Lett. 69, 1664-1667 (1992).

${ }^{8}$ The term (or concept of) 'Spherical (3D) Aromaticity' has been introduced by Hirsch ${ }^{22}$ and Karttunen et al. ${ }^{5}$ to describe certain [magnetic shielding] consequences of such electron shells.
${ }^{9}$ The $\mathrm{L}=5$ ("H") shell will assume particular significance in the discussion to follow, as it relates to the forms $I-\mathrm{Au}_{72}$ as well as $I-\mathrm{Au}_{60}\left[12^{-}\right]$stability/electronic gap.

${ }^{10}$ H.-C. Weissker, H. B. Escobar, V. D. Thanthirige, K. Kwak, D. Lee, G. Ramakrishna, R. Whetten, and X. López-Lozano, "Information on quantum states pervades the visible spectrum of the ubiquitous $\mathrm{au}_{144}(\mathrm{sr})_{60}$ gold nanocluster," Nature Communications 5, 3785 (2014).

${ }^{11}$ A. Tlahuice-Flores, D. M. Black, S. B. Bach, M. Jose-Yacamán, and R. L. Whetten, "Structure \& bonding of the gold-subhalide cluster $i$-au $144 \mathrm{Cl}_{60}$ [z]," Physical Chemistry Chemical Physics 15, 19191-19195 (2013).

${ }^{12}$ D. Bahena, N. Bhattarai, U. Santiago, A. Tlahuice, A. Ponce, S. B. H. Bach, B. Yoon, R. L. Whetten, U. Landman, and M. JoseYacamán, "Stem electron diffraction and high-resolution images used in the determination of the crystal structure of the $a_{144}(\mathrm{sr})_{60}$ cluster," The Journal of Physical Chemistry Letters 4, 975-981 (2013), http://pubs.acs.org/doi/pdf/10.1021/jz400111d.

${ }^{13}$ O. López-Acevedo, J. Akola, R. L. Whetten, H. Grönbeck, and H. Häkkinen, "Structure and bonding in the ubiquitous icosahedral metallic gold cluster $\mathrm{au}_{144}(\mathrm{sr})_{60}$," The Journal of Physical Chemistry C 113, 5035-5038 (2009), http://pubs.acs.org/doi/pdf/10.1021/jp8115098.

${ }^{14}$ N. Yan, N. Xia, L. Liao, M. Zhu, F. Jin, R. Jin, and Z. Wu, "Unraveling the long-pursued au144 structure by x-ray crystallography," Science Advances 4, eaat7259 (2018)

${ }^{15}$ Z. Lei, J.-J. Li, X.-K. Wan, W.-H. Zhang, and Q.-M. Wang, "Isolation and total structure determination of an all-alkynyl-protected gold nanocluster au144," Angewandte Chemie International Edition 57, 8639-8643 (2018).

${ }^{16}$ R. L. Whetten, H.-C. Weissker, J. J. Pelayo, S. M. Mullins, X. LópezLozano, and I. L. Garzón, "Chiral-icosahedral (i) symmetry in ubiquitous metallic cluster compounds (145a,60x): Structure and bonding principles," Accounts of Chemical Research 52, 34-43 (2019), https://doi.org/10.1021/acs.accounts.8b00481.

${ }^{17}$ R. L. Whetten, J. T. Khoury, M. M. Alvarez, S. Murthy, I. Vezmar, Z. Wang, P. W. Stephens, C. L. Cleveland, W. Luedtke, and U. Landman, "Nanocrystal gold molecules," Advanced Materials 8, 428-433 (1996).

${ }^{18}$ N. T. Tran, D. R. Powell, and L. F. Dahl, "Nanosized pd145 (co) x (pet3) 30 containing a capped three-shell 145-atom metal-core geometry of pseudo icosahedral symmetry," Angewandte Chemie International Edition 39, 4121-4125 (2000)

${ }^{19}$ N. K. Chaki, Y. Negishi, H. Tsunoyama, Y. Shichibu, and T. Tsukuda, "Ubiquitous 8 and 29 kda gold:alkanethiolate cluster compounds: Massspectrometric determination of molecular formulas and structural implications," Journal of the American Chemical Society 130, 8608-8610 (2008), pMID: 18547044, https://doi.org/10.1021/ja8005379.

${ }^{20}$ M. Walter, J. Akola, O. López-Acevedo, P. D. Jadzinsky, G. Calero, C. J. Ackerson, R. L. Whetten, H. Grönbeck, and H. Häkkinen, "A unified view of ligand-protected gold clusters as superatom complexes," Proceedings of the National Academy of Sciences 105, 9157-9162 (2008).

${ }^{21}$ W. Huang, M. Ji, C.-D. Dong, X. Gu, L.-M. Wang, X. G. Gong, and L.-S. Wang, "Relativistic effects and the unique low-symmetry structures of gold nanoclusters," ACS Nano 2, 897-904 (2008), http://dx.doi.org/10.1021/nn800074b.

${ }^{22} \mathrm{~A}$. Hirsch, Z. Chen, and H. Jiao, "Spherical aromaticity in $i_{h}$ symmetrical fullerenes: the $2(n+1) 2$ rule," Angewandte Chemie International Edition 39, 3915-3917 (2000).

${ }^{23}$ J. Wang, J. Jellinek, J. Zhao, Z. Chen, R. B. King, and P. von Rague Schleyer, "Hollow cages versus space-filling structures for mediumsized gold clusters: the spherical aromaticity of the $a_{50}$ cage," The Journal of Physical Chemistry A 109, 9265-9269 (2005).

${ }^{24}$ H. W. Kroto, J. R. Heath, S. C. O'Brien, R. F. Curl, and R. E. Smalley, "C $\mathrm{C}_{60}$ : Buckminsterfullerene," Nature 318, 162-163 (1985).

${ }^{25}$ J. M. Soler, M. R. Beltrán, K. Michaelian, I. L. Garzón, P. Ordejón, D. Sánchez-Portal, and E. Artacho, "Metallic bonding and cluster structure," Phys. Rev. B 61, 5771-5780 (2000).

${ }^{26}$ J. M. Soler, E. Artacho, J. D. Gale, A. García, J. Junquera, P. Ordejón, and D. Sánchez-Portal, "The siesta method for ab initio order-n materials simulation," Journal of Physics: Condensed Matter 14, 2745 (2002).

${ }^{27} \mathrm{~N}$. Troullier and J. L. Martins, "Efficient pseudopotentials for plane-wave calculations,” Phys. Rev. B 43, 1993-2006 (1991).

${ }^{28}$ J. P. Perdew, K. Burke, and M. Ernzerhof, "Generalized gradient approximation made simple,” Phys. Rev. Lett. 77, 3865-3868 (1996). 
${ }^{29}$ P. A. Clayborne, O. López-Acevedo, R. L. Whetten, H. Grönbeck, and H. Häkkinen, "The $\mathrm{al}_{50} \mathrm{cp}_{12}^{*}$ cluster-a 138-electron closed shell $(\mathrm{l}=6)$ superatom," European Journal of Inorganic Chemistry 2011, 2649-2652 (2011). 30"Jmol: an open-source java viewer for chemical structures in $3 \mathrm{~d}$. http:www.jmol.org," .

${ }^{31}$ R. J. C. Batista, M. S. C. Mazzoni, L. O. Ladeira, and H. Chacham, "Firstprinciples investigation of au-covered carbon fullerenes," Phys. Rev. B 72 085447 (2005)

${ }^{32}$ T. Martin, "Shells of atoms," Physics Reports 273, 199 - 241 (1996)

${ }^{33}$ J. Li, X. Li, H.-J. Zhai, and L.-S. Wang, "Au 20 : A tetrahedral cluster," Science 299, 864-867 (2003).

${ }^{34}$ I. Chakraborty, A. Govindarajan, J. Erusappan, A. Ghosh, T. Pradeep, B. Yoon, R. L. Whetten, and U. Landman, "The superstable 25 kda monolayer protected silver nanoparticle: Measurements and interpretation as an icosahedral $\mathrm{ag}_{152}\left(\mathrm{sch}_{2} \mathrm{ch}_{2} \mathrm{ph}\right)_{60}$ cluster," Nano Letters 12, 5861-5866 (2012), pMID: 23094944, http://dx.doi.org/10.1021/nl303220x.

${ }^{35} \mathrm{~K}$. Heinze and H. Lang, "Ferrocene-beauty and function," Organometallics 32, 5623-5625 (2013).

${ }^{36}$ J. J. Pelayo, R. L. Whetten, and I. L. Garzón, "Geometric quantification of chirality in ligand-protected metal clusters," The Journal of Physical Chemistry C 119, 28666-28678 (2015)

${ }^{37}$ D. Bochicchio and R. Ferrando, "Size-dependent transition to highsymmetry chiral structures in $\mathrm{AgCu}, \mathrm{AgCo}, \mathrm{AgNi}$, and AuNi nanoalloys," Nano Letters 10, 4211-4216 (2010).

${ }^{38}$ V. Z. Kresin and Y. N. Ovchinnikov, "Giant strengthening of superconducting pairing in metallic nanoclusters: large enhancement of $\mathrm{t}_{c}$ and potential for room-temperature superconductivity," Physics-Uspekhi 51, 427 435 (2008) 

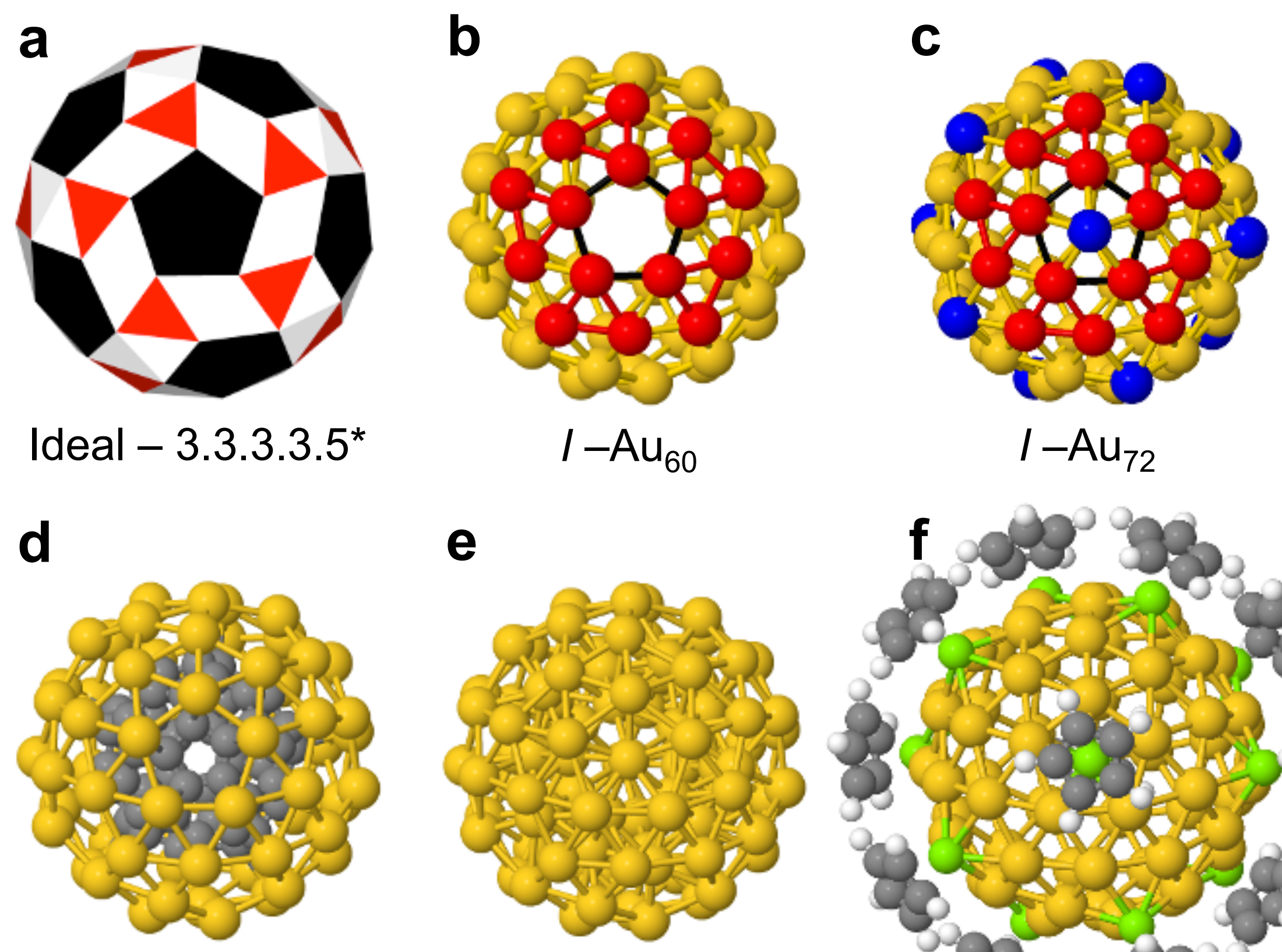

e
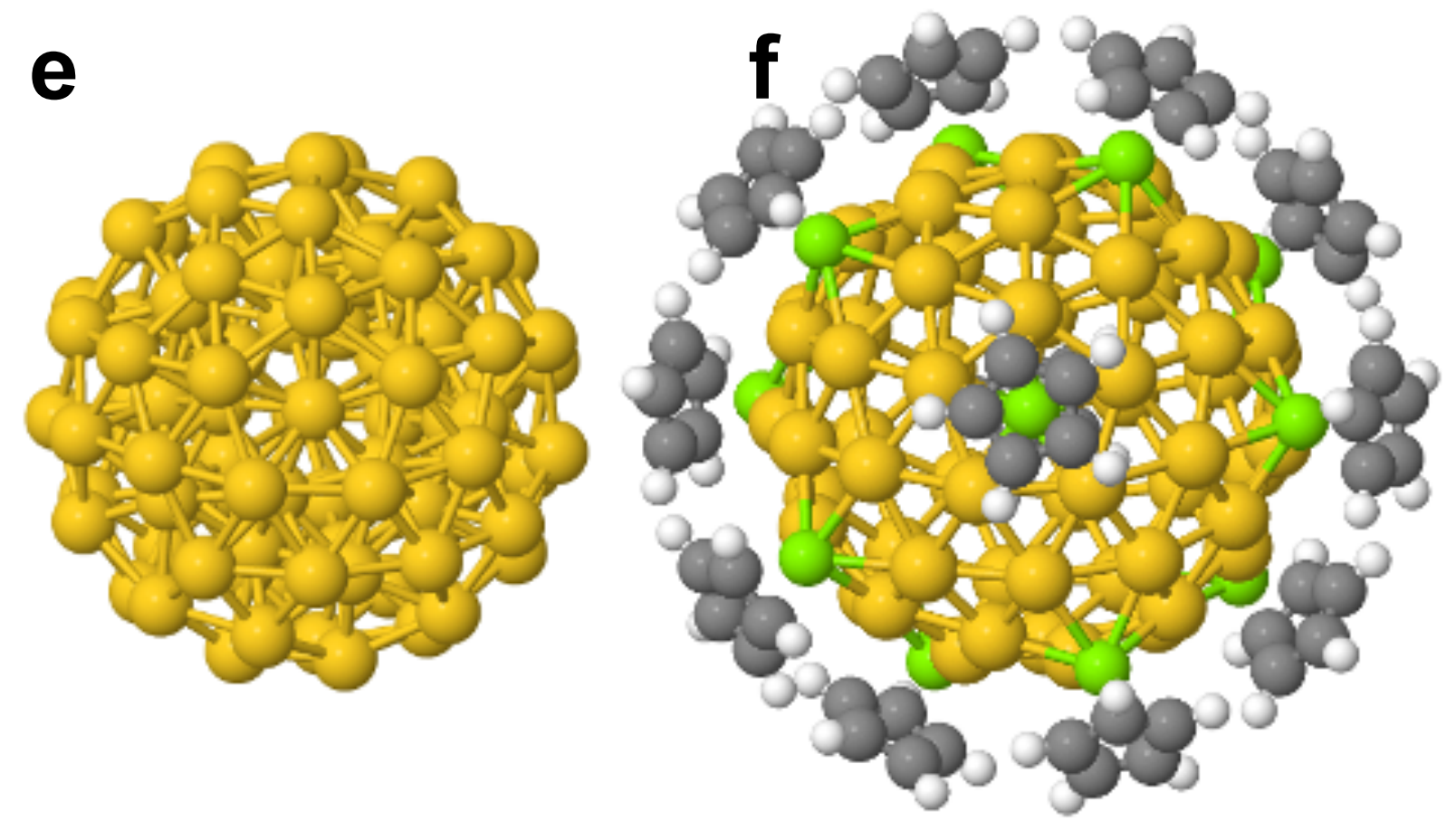

$I_{h}-\mathrm{C}_{60} @ I-\mathrm{Au}_{60}$

$I_{h}-\mathrm{Au}_{32} @ I-\mathrm{Au}_{60}{ }^{2+}$

$$
\text { I-Au } \mathrm{u}_{60}(\mathrm{MgCp})_{12}
$$


a

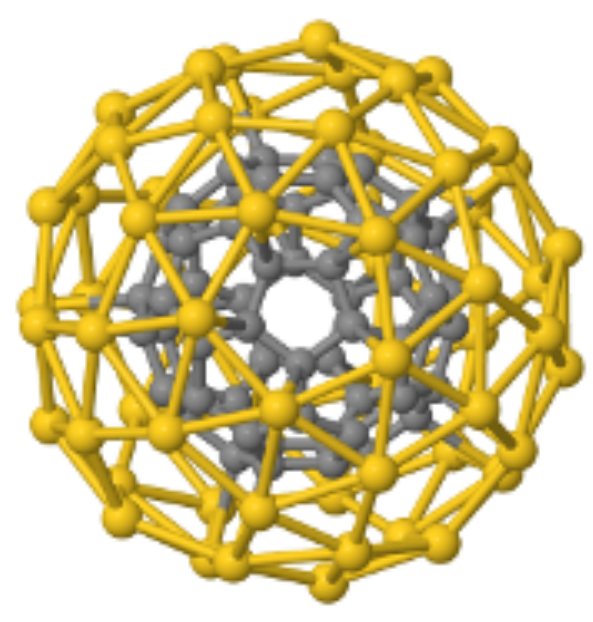

$D_{5}-\mathrm{C}_{60} @ A u_{60}$

d

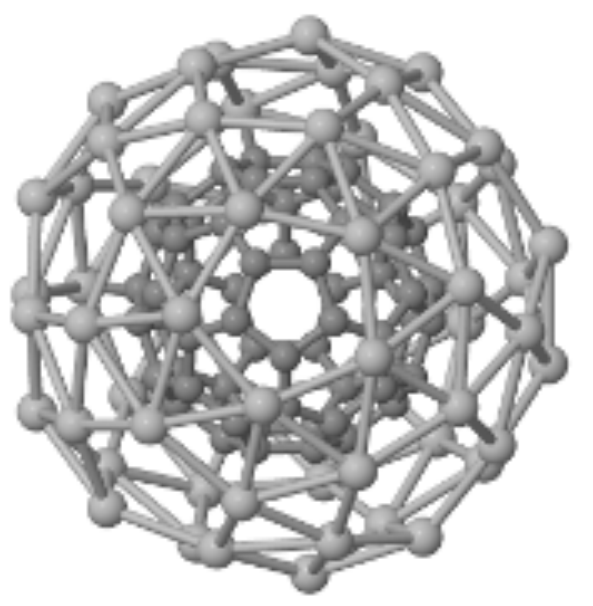

$D_{5}-\mathrm{C}_{60} @ \mathrm{Ag}_{60}$ b

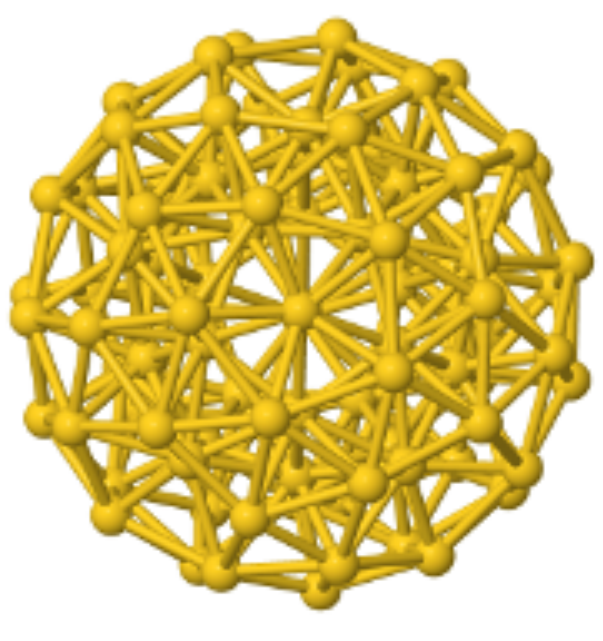

I -Au $32 @ \mathrm{Au}_{60}{ }^{2+}$

e

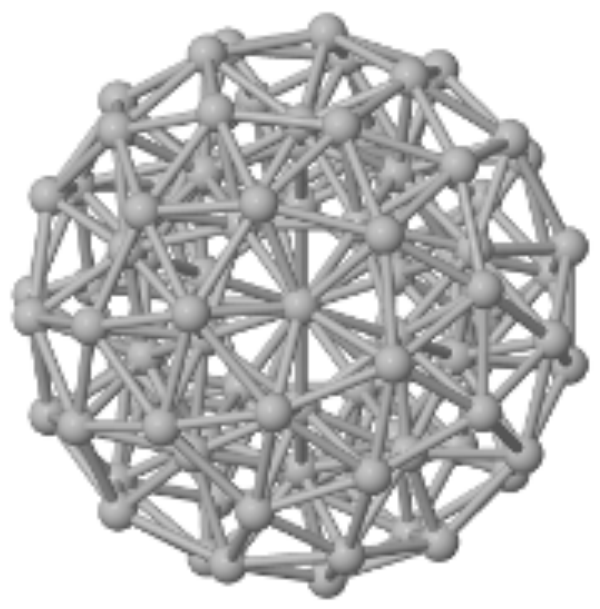

I - $\mathrm{Ag}_{32} @ \mathrm{Ag}_{60}{ }^{2+}$

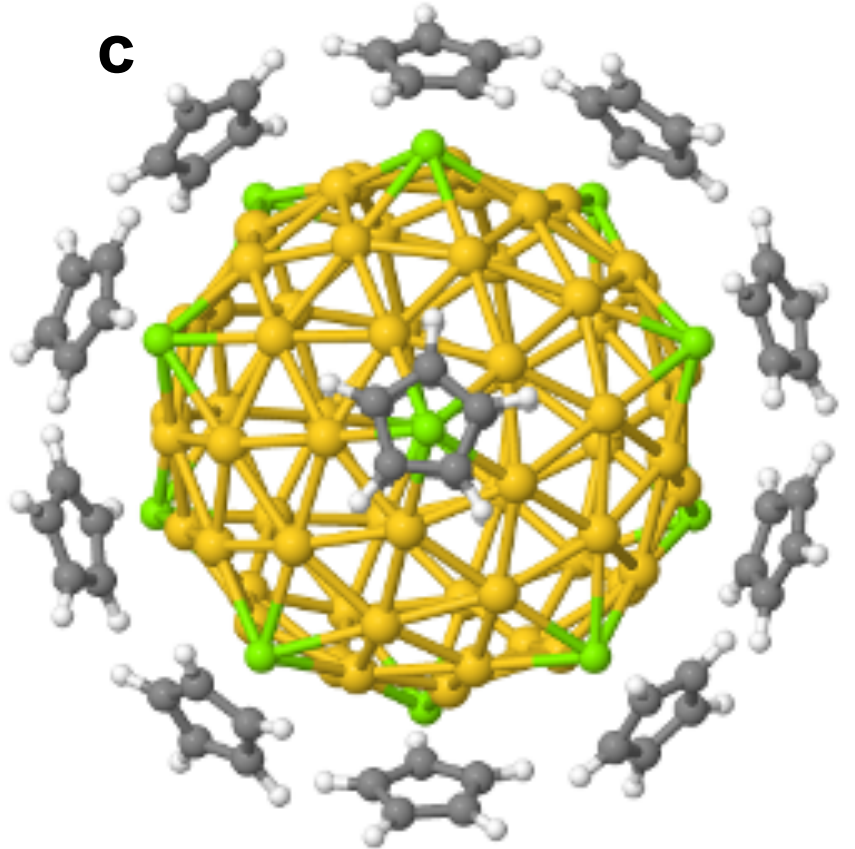

$$
C_{5}-\mathrm{Au}_{60}(\mathrm{MgCp})_{12}
$$

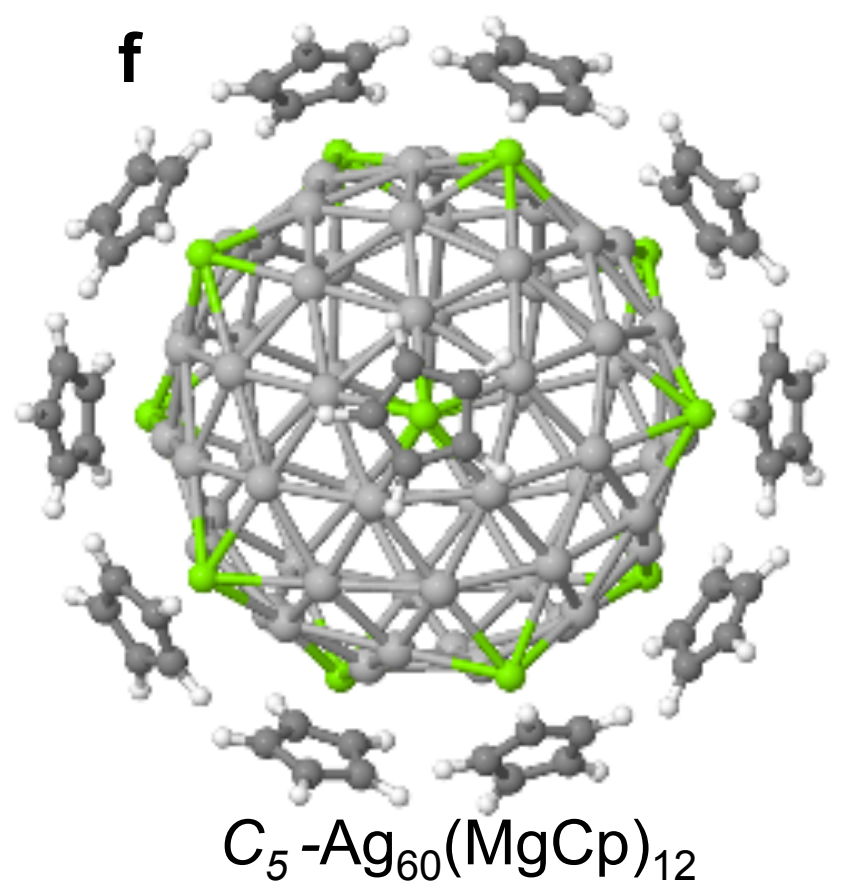




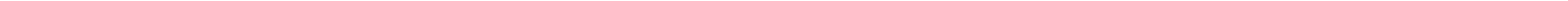



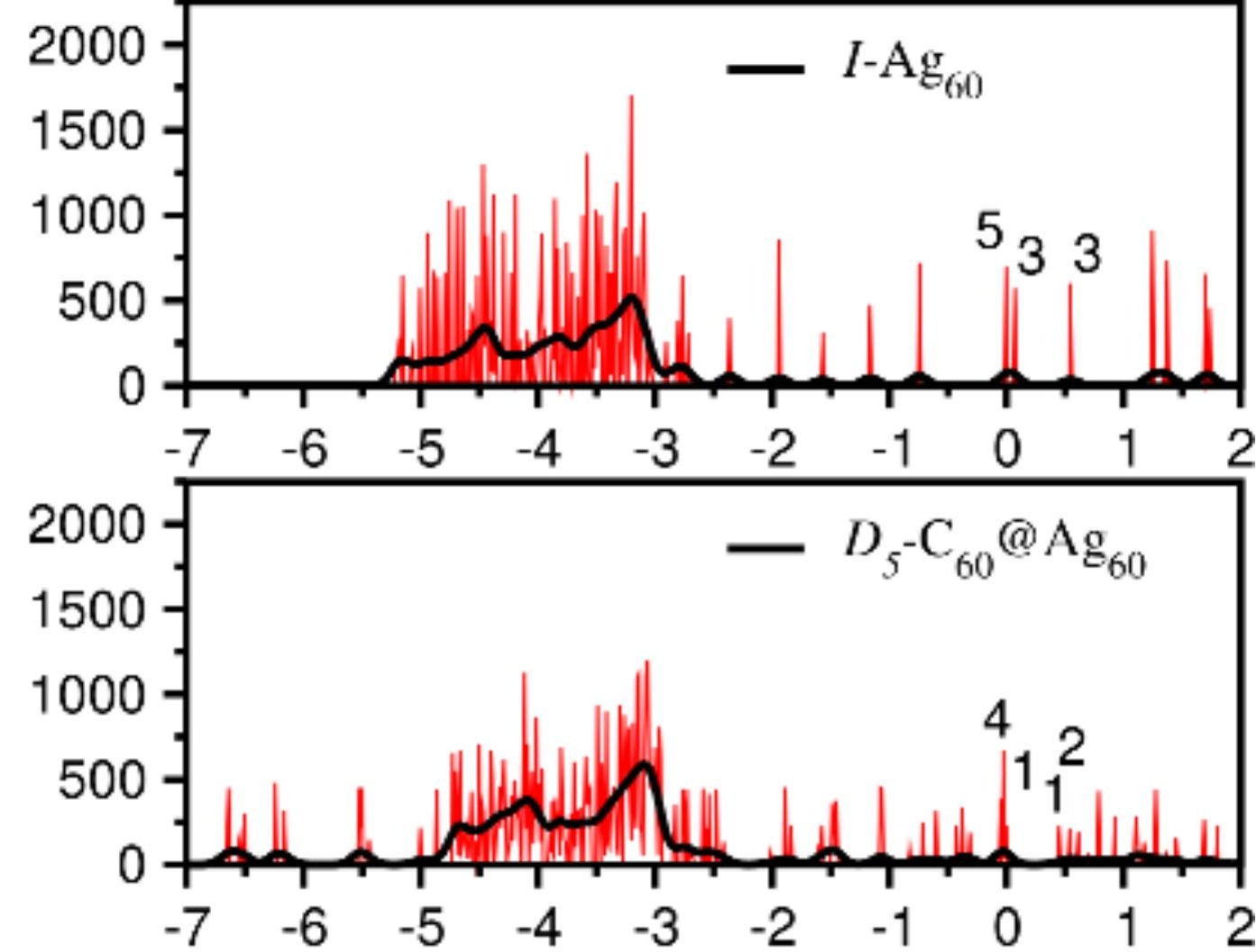

c $2000-1-I-\mathrm{Ag}_{32} @ \mathrm{Ag}_{60}^{2+}$

d

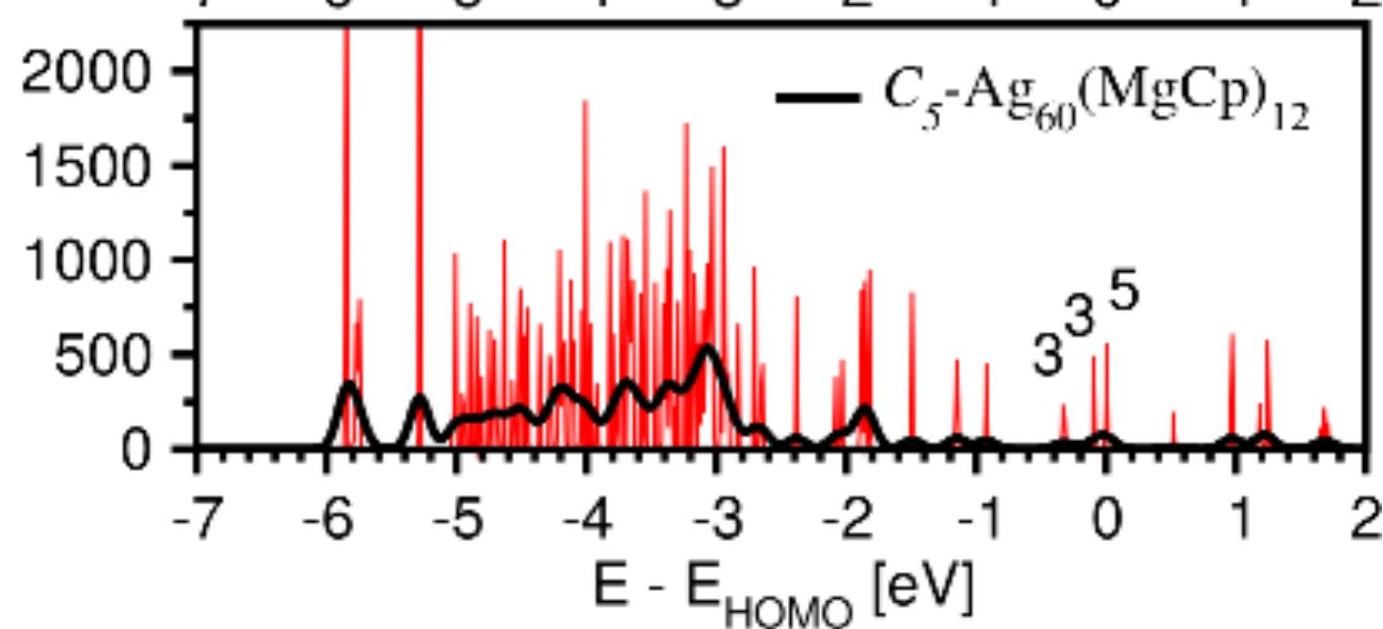

